\title{
Adsorption performance and mechanisms of mercaptans removal from gasoline oil using core- shell AC-based adsorbents: Role of intra-particles space
}

\section{Pamphile Ndagijimana}

Institute of Urban Environment Chinese Academy of Sciences

Xuejiao Liu

Institute of Urban Environment Chinese Academy of Sciences

Zhiwei Li

Institute of Urban Environment Chinese Academy of Sciences

Zhenjiao Xing

Institute of Urban Environment Chinese Academy of Sciences

Beibei Pan

Institute of Urban Environment Chinese Academy of Sciences

Guangwei Yu

Institute of Urban Environment Chinese Academy of Sciences

Yin Wang ( $\square$ yinwang@iue.ac.cn )

Institute of Urban Environment Chinese Academy of Sciences

\section{Research Article}

Keywords: Mercaptans removal, Gasoline oil, Adsorption, Intra-particles space, Core-shell activated carbon

Posted Date: March 30th, 2021

DOl: https://doi.org/10.21203/rs.3.rs-326696/v1

License: (c) (i) This work is licensed under a Creative Commons Attribution 4.0 International License. Read Full License

Version of Record: A version of this preprint was published at Environmental Science and Pollution Research on July 10th, 2021. See the published version at https://doi.org/10.1007/s11356-021-15075-y. 
1 Adsorption performance and mechanisms of mercaptans removal from gasoline oil using core-shell

2 AC-based adsorbents: Role of intra-particles space

3 Pamphile Ndagijimana ${ }^{\mathrm{a}}$, Xuejiao Liu, ${ }^{\mathrm{a} *}$, Zhiwei $\mathrm{Li}^{\mathrm{a}}$, Zhenjiao Xing ${ }^{\mathrm{a}}$, Beibei Pan ${ }^{\mathrm{a}}$, Guangwei Yu $\mathrm{u}^{\mathrm{a}}$, Yin

$4 \quad$ Wang $^{\mathrm{a}, *}$

$5 \quad{ }^{a}$ CAS Key Laboratory of Urban Pollutant Conversion, Institute of Urban Environment, Chinese Academy

6 of Sciences, Xiamen 361021, China

7

8

$9 \quad{ }^{*}$ Corresponding authors. E-mail address: yinwang@iue.ac.cn (Y. Wang), xjliu@iue.ac.cn (X.J. Liu)

10

11

12

13

14

15

16 
Sulfur compound detection such as mercaptans in liquid fuels is undesirable because sulfur is the main 19 sourcing emission of sulfur oxide $\left(\mathrm{SO}_{\mathrm{x}}\right)$ into the air. The use of activated carbon $(\mathrm{AC})$ has proven to 20 efficiently remove mercaptans. In the meantime, it is limited by the generation of the second pollution in 21 oil, and the difficulties of recovery and regeneration. To address these issues, a core-shell structured AC 22 with high mechanical strength and big intra-particles space were synthesized and demonstrated to 23 efficiently remove organic pollutants from an aqueous solution without generation of the second pollution

24 in our previous work. However, the performance, characteristics, and mechanism of mercaptans adsorption 25 from gasoline oil by core-shell structured AC was still unclear. In this study, the mercaptans adsorption 26 behaviors using core-shell powdered activated carbon (CSAC) and core-shell granulated activated carbon 27 (CSGAC), along with raw PAC, PAC-core, raw GAC, and GAC-core were carried out. The results showed 28 that both the CSAC and CSGAC adsorbents effectively removed sulfur-based pollutants and were provided 29 with good recovery and recyclability without second pollution in gasoline oil. The CSGAC exhibited a 30 higher mercaptans removal efficiency compared to those of CSAC as a result of the bigger intra-particles 31 space. PAC-based adsorbents, presented the shrinking of removal efficiency after regeneration. The 32 Pseudo-second-order kinetics and Langmuir isotherms models were dominated for mercaptans adsorption 33 by both CSAC and CSGAC. Furthermore, the interactions between mercaptans and the composites were 34 probably ascribed to the Van der Waals force, hydrophobic compatibility, pore texture, and $\pi$ - $\pi$ dispersion 35 interaction.

36 Keywords: Mercaptans removal, Gasoline oil, Adsorption, Intra-particles space, Core-shell activated 37 carbon 


\section{Introduction}

The most common and biggest source of energy in the world is from fossil fuels and crude oil. The main parts of crude oil include gasoline, diesel, and jet fuel, which are used as transportation fuels (Srivastava, 2012).

42 The use of liquid fuels (gasoline, diesel, kerosene, jet fuel, etc.) in industrial, transport, and domestic activities for energy production constitute an important source of air pollution (Fan et al., 2013; Shen et al., 2009). However, when using these fuels, the release of persistent impurities, especially for small organic sulfur compounds (mercaptans, thioethers, disulfides, and others) is still an issue that is raising concern (Daraee et al., 2021; Mahmoudabadi, 2021; Sun et al., 2017). Mercaptans (thiol) are featured by unbearable odor as a result of sulfur-contained compounds (Bashkova et al., 2002). They are the most harmful sulfurcarry compounds in gasoline, not only due to their unpleasant-smell and corroding (Gao et al., 2009; Zhang et al., 2013) but also to the degrading gasoline quality by enhancing the production of gum (Wang et al., 2014). The sulfur compounds in gasoline could generate pollution in the environment because their 51 combustion emits sulfur dioxide in the atmosphere, which generates acid rain leading to environmental 52 hazards (Daraee et al., 2021; Mguni et al., 2019; Mohebbi and Mohebbi, 2017).

The removal of mercaptans from fuel has been a global challenge. Various technologies such as 54 adsorption, extraction, bioprocesses, and oxidation for reducing the sulfur compound from fuel are 55 introduced (Dehghan and Anbia, 2017; Rodríguez-Cabo et al., 2014; Wang et al., 2014). For example, the 56 hydrodesulfurization technique could treat such pollutants, but it reduces the octane number of gasoline 57 (Wang et al., 2014), leading to the degradation of the quality of the resultant gasoline product (Huang et al., 58 2018). High temperature and pressure are also required in this technique (Farzin Nejad and Miran Beigi, 59 2015). Catalytic oxidation is another limitation for other techniques due to the conversion of mercaptans 60 disulfides in alkaline media through oxidation with air (Koncsag and Barbulescu, 2008; Rodríguez-Cabo et al., 2014; Shiraishi et al., 2002). It has been reported that the adsorption is effective for mercaptans removal from gasoline (Aguiar and Coelho, 2017; Mguni et al., 2019) resulting from its affordable operations and environmental-friendliness. Activated carbon (AC) is a popular adsorbent in removing the mercaptans 
(Bashkova et al., 2002; Mguni et al., 2019), which is considered as a good adsorbent in pollutant control (Lee et al., 2010). However, the limitations such as difficulty to recovery from the liquid phase, causing the second pollution in the liquid phase, and low recyclability are the main challenges of using $\mathrm{AC}$ in the adsorption process. To address these issues, our group synthesized novel recyclable AC materials (coreshell structured powdered and granulated AC, i.e., CSAC and CSGAC) recently. The results indicated that pharmaceuticals and personal care products (PPCPs) could be efficiently removed from an aqueous solution by these composites (Ndagijimana et al., 2020, 2019a, 2019b). In the meantime, the material further presented a good regeneration and recover-ability. Nonetheless, our previous studies focused on the organic pollutants in the aquatic phase rather than the mercaptans in organic solvents, which probably results in different adsorption behaviors and mechanisms. In addition, comparisons of mercaptans adsorption by CSAC and CSGAC were not carried out. Accordingly, to support the real implementations of core-shell AC composites, it is indispensable to disclose the mercaptans adsorption behaviors from an organic solvent by CSAC and CSGAC, as well as to depict the influence of core-shell AC with AC core produced by AC in different particle size. It is equally important to evaluate the performance of regeneration and recoverability of CSAC and CSGAC in an organic solvent.

Therefore, based on the previous studies (Ndagijimana et al., 2020, 2019a, 2019b), the objectives of this work were as follows: (i) to compare the performance of CSAC, CSGAC, PAC, PAC-core, GAC, and GAC-core in adsorbing mercaptans; (ii) to evaluate and compare the regeneration and recover-ability of CSAC, CSGAC, PAC, PAC-core, GAC, and GAC-core; (iii) to explore interaction mechanisms via investigating the adsorption kinetics, isotherms, and surface composition of adsorbents before and after adsorption; (iv) to test effects of coexisting mercaptans on the adsorption performance. This work is expected to be in favor of providing an effective strategy for mercaptans' removal from fuel. 


\section{Materials and methods}

\subsection{Chemicals and reagents}

The n-hexane was used as the solvent. The sulfur compounds were purchased from Aldrich, including ethyl-mercaptan, propanethiol, and 1-butanethiol with a purity of 98, 98, and 99\%, respectively. Table 1 presents the structure and physicochemical properties of mercaptans.

\subsection{Preparation and characterization}

As described in our recent works (Ndagijimana et al., 2020, 2019a, 2019b), the PAC-core and GACcore were prepared by mixing the PAC (100 mesh) and GAC ( $2 \mathrm{~mm})$ with $8 \%$ and $15 \%$ of natural binder from cassava, respectively. As for the shell, coal fly ash with 100 mesh and kaolinite with 400 mesh were selected owing to the formation of CSAC with small intra-particles space in the shell to protect PAC from degeneration (Ndagijimana et al., 2019a, 2019b), whereas, the coal fly ash with 100 mesh and 100 mesh of kaolinite were selected to the synthesize CSGAC with large porous channels (Ndagijimana et al., 2020). The AC-core after drying was coated by the mixture of kaolinite and cola fly ash as the shell. The samples were dried and then sintered at $1250^{\circ} \mathrm{C}$ followed by cooling at room temperature. Thereafter, the samples were characterized by the ZL-8001 computer servo universal material testing machine (China). The materials with high mechanical strength (2.41 and 2.0 MPa) were selected and used to remove mercaptans. The morphology and the crystalline were analyzed by field emission scanning electron microscopy (SEM) and X-ray diffraction (XRD), respectively. The surface area, pore size, and pore volume were tested by Brunauer-Emmett-Teller (BET). The details of characterization techniques for AC-based adsorbents were described in a recent report (Ndagijimana et al., 2020, 2019a, 2019b).

\subsection{Batch adsorption}

The preparation of mercaptans solution was carried out as follows: Firstly, the standard hexane solution containing $1000 \mathrm{ppb}$ mercaptans compound was prepared in the bottles of $100 \mathrm{~mL}$ by dissolving the accurate weight of sulfur compounds in n-hexane solvent. Then, the bottles with rubber caps and aluminum rings were used to avoid evaporation and surroundings. This solution prepared for each compound was used to prepare the desired concentration of each sulfur compound. 
A batch adsorption study was carried out by using $0.24 \mathrm{~g}$ of CSAC, $0.28 \mathrm{~g}$ of CSGAC, $0.05 \mathrm{~g}$ of PAC-

117 based adsorbents (PAC and PAC-core), and $0.03 \mathrm{~g}$ of GAC-based adsorbents (GAC and GAC-core). Each

118 adsorbent was taken into a bottle of $100 \mathrm{~mL}$ and then sealed with rubber caps. Then, $50 \mathrm{~mL}$ of each sulfide

119 compound solution was introduced into the bottles which contain the adsorbents. The cellulose membrane

120 with $0.45 \mu \mathrm{m}$ pore size was used for filtration of the supernatant after shaking the bottle samples with a

121 speed of $200 \mathrm{rpm}$ at $25^{\circ} \mathrm{C}$. Then the supernatant was analyzed by Gas Chromatograph (GC). The detection

122 conditions of GC contain detector (Mass spectrometric detector), oven temperature (45-240 $\left.{ }^{\circ} \mathrm{C}\right)$, injector

123 temperature $\left(220^{\circ} \mathrm{C}\right)$, and detector temperature $\left(230^{\circ} \mathrm{C}\right)$. The filtrate was proved with Gas Chromatography-

124 Mass Spectrometry systems via an AOC-20i autosampler (Agilent 7890B-Agilent 5977B, Agilent, USA)

125 and with the help of GS-GASPRO capillary column $(30 \mathrm{~m} \times 320 \mu \mathrm{m} \times 0 \mu \mathrm{m}, \mathrm{J} \& \mathrm{~W}$ Scientific Inc, USA $)$

$126\left(30 \mathrm{~m} \times 320 \mu \mathrm{m} \mathrm{x}_{0} \mu \mathrm{m}\right)$. Helium was utilized as the carrier gas and the mobile phase was hexane. The

127 retention time of ethyl mercaptan, 1-propanethiol, and 1-butanethiol were 6, 7, and 9 min, respectively.

Effect of adsorbent dosage: One, two, and three balls of core-shell ACs, 0.03, 0.05, and $0.10 \mathrm{~g}$ for both

129

130

PAC and GAC-based adsorbents were used. The initial concentration of mercaptans was $2000 \mathrm{ppb}$ and the adsorption time was $600 \mathrm{~min}$.

Effect of initial concentration: The initial concentration of 800, 900, 1000, 1200, 1500, and $2000 \mathrm{ppb}$ for each sulfide compound were prepared. The samples were withdrawn at a certain adsorption time.

Effect of contact time: The initial concentration of mercaptans was $1000 \mathrm{ppb}$. The supernatants samples were withdrawn at a certain interval of time.

Effect of temperature: The adsorption experiments were carried out at the temperature of 25, 30, 40, $60^{\circ} \mathrm{C}$, respectively. The initial concentration of mercaptans was $1000 \mathrm{ppb}$.

Regeneration of adsorbents: The spent adsorbents were regenerated at $600^{\circ} \mathrm{C}$ for further adsorption process.

The amount of adsorption at equilibrium, at time $t$, and the percentage of mercaptans removal were calculated via equations (1), (2), and (3), respectively. 
$141 \quad \mathrm{q}_{\mathrm{e}}=\frac{\left(\mathrm{c}_{\mathrm{o}}-\mathrm{c}_{\mathrm{e}}\right) \times \mathrm{V}}{\mathrm{M}}$

$142 \quad \mathrm{q}_{\mathrm{t}}=\frac{\left(\mathrm{C}_{0}-\mathrm{C}_{\mathrm{t}}\right) \times \mathrm{V}}{\mathrm{M}}$

$143 \quad \mathrm{R}=\frac{\left(\mathrm{C}_{\mathrm{o}}-\mathrm{C}_{\mathrm{e}}\right) \times 100}{\mathrm{C}_{\mathrm{o}}}$

144 where $\mathrm{q}_{\mathrm{e}}$ and $\mathrm{q}_{\mathrm{t}}\left(\mathrm{mgS} \mathrm{g}^{-1}\right)$ are the adsorption capacity at equilibrium and time $\mathrm{t}, \mathrm{R}(\%)$ is the removal 145 percentage, and $\mathrm{C}_{0}$ and $\mathrm{C}_{\mathrm{e}}$ are the liquid-phase concentrations of mercaptans at initial time and equilibrium, 146 respectively. V (L) is the volume of the solution and $\mathrm{M}(\mathrm{g})$ is the mass of the CSAC.

147 2.4. Adsorption isotherms and kinetics

148 The capacity of mercaptans adsorption and isotherms parameters were calculated in virtue of the 149 adsorption isotherms model. The details for the calculation of the isotherm parameters were presented in 150 studies (Barzamini et al., 2014).

The Langmuir model and Freundlich isotherm are expressed as follows: equation (4) and (5):

$152 \quad \frac{\mathrm{C}_{\mathrm{e}}}{\mathrm{q}_{\mathrm{e}}}=\frac{1}{\mathrm{~K}_{\mathrm{L}} \mathrm{q}_{\mathrm{m}}}+\frac{\mathrm{C}_{\mathrm{e}}}{\mathrm{q}_{\mathrm{m}}}$

$\ln \mathrm{q}_{\mathrm{e}}=\ln \mathrm{k}_{\mathrm{F}}+\left(\frac{1}{\mathrm{n}}\right) \ln \mathrm{Ce}$

154 The corresponding introductions of the parameters were found in lots of studies (Ndagijimana et al., 2019a).

155 For further studying the adsorption characteristics, three kinetics models were applied, including pseudo156 first-order, pseudo-second-order, and intra-particle models. The equations (6), (7), and (8) below were 157 applied to fit the kinetics data.

$158 \quad$ Pseudo-first order model: $\quad \ln \left(\mathrm{q}_{\mathrm{e}}-\mathrm{q}_{\mathrm{t}}\right)=\ln \mathrm{q}_{\mathrm{t}}-\mathrm{k}_{1} \mathrm{t}$

159 Pseudo-second order model: $\frac{\mathrm{t}}{\mathrm{q}_{\mathrm{t}}}=\frac{1}{\mathrm{k}_{2} \mathrm{q}_{\mathrm{e}}^{2}}+\frac{\mathrm{t}}{\mathrm{q}_{\mathrm{e}}}$

$160 \quad$ Intraparticle diffusion: $\quad \mathrm{q}_{\mathrm{t}}=\mathrm{k}_{\mathrm{dif}} \mathrm{t}^{1 / 2}+\mathrm{C}$

161 Similarly, the introductions of the corresponding parameters were described in the study (Liu et al., 2019).

\section{3. Results and Discussion}

\subsection{Characterizations}

The physical image, the morphological information of CSAC, and its core and shell are presented in

Fig.1. Fig. 1a shows that the shell of the materials is porous, and favorable for adsorbate solution to diffuse 
to the inner AC core. For Fig. 1b as explained in previous work (Ndagijimana et al., 2019b), after

167 optimization of the shell particle size, the inter-particles space of the shell was small to prevent the PAC 168 core from release of the part of PAC to the solution. In addition, Fig. 1c illustrates that the shell with larger 169 inter-particles space is favorable for the protection of GAC and simultaneously facilitates the high rate of 170 mass diffusion which is good evidence for increasing removal efficiency for CSGAC. Figs. 1d-g present 171 the physical images of the CSAC, CSGAC, GAC-core, and PAC-core, respectively. As shown in the figure, 172 the GAC-core presented the larger intra-particles space compared to that of PAC, which is owing to the 173 larger size in GAC (2 mm). Figs. 1h and I show that the pore structure of the PAC core and GAC core after 174 the sintering and the detail is illustrated in our recently reported work (Ndagijimana et al., 2020). The 175 structure of the materials indicates the presence of pores which is beneficial for the adsorption of the 176 aforementioned pollutants in gasoline oil.

177 The textural structure such as specific surface area calculated by BET equation ( $\left.\mathrm{S}_{\mathrm{BET}}\right)$ and pore 178 distribution of the samples was analyzed and presented in Table 2 and Fig. 2, respectively. As illustrated in 179 Table 2, the CSAC presented a higher $\mathrm{S}_{\mathrm{BET}}$ compared to that of CSGAC. Moreover, $\mathrm{S}_{\mathrm{BET}}$ of the PAC-core and GAC-core detached from shell were higher than those of PAC and GAC, respectively, because of 181 sintering of the sample at high temperature $\left(1250^{\circ} \mathrm{C}\right)$. Fig. 2 illustrates the presence of pore distribution and 182 pore size of AC-based adsorbents. It evidences the presence of micropores and mesopores for all AC-based 183 adsorbents (Figs. 2a and b), and macropores especially for CSGAC (Figs. 2c and d). The macropores 184 facilitate the penetration of the adsorbate molecular from the bulk solution to the shell and then to the inner 185 core.

\subsection{Application for mercaptans removal}

187 3.2.1. Effect of adsorbent dosage

One, two, and three balls of CSAC and CSGAC were used to investigate the influence of adsorbent dosage (Fig. 3a). As shown in the figure, the removal efficiency of mercaptans and the dosage of adsorbents were positively correlated. For instance, the removal efficiency was 33, 67, and $100 \%$ for ethanethiol and 
and 41,75 , and $100 \%$ of 1-Butanethiol were removed by CSGAC, respectively. These results presented that both the removal efficiencies for ethanethiol and 1-butanethiol by CSGAC were higher than that of CSAC. This phenomenon is caused by the large intra-particles space in the shell and GAC-core for CSGAC. These intra-particles space could facilitate contact between mercaptans molecular and active sites of GACcore inside the shell. Despite a low removal mercaptans efficiency by CSAC, it should be noted that as-

197 synthesized protected AC materials showed a promising future for removing mercaptans from the gasoline 198 oil. As illustrated in Figs. $3 \mathrm{~b}$ and $\mathrm{c}$, the dosages used in this experiment were $0.03,0.05$, and $0.10 \mathrm{~g}$ for 199 PAC, PAC-core, GAC, and GAC-core, respectively. The results also showed that the removal efficiency increased with adding more adsorbents as a result of more active sites. In addition, the performance of mercaptans adsorption by PAC-core and GAC-core were better than those of their counterparts (PAC and GAC). This phenomenon is likely due to the higher $S_{\mathrm{BET}}$ after sintering treatment at high temperatures. Accordingly, the large intra-particles space in shell and AC-core and high $\mathrm{S}_{\mathrm{BET}}$ are key factors enhancing the adsorption of mercaptans using CSGAC.

\subsubsection{Effect of contact time}

The effect of contact time on mercaptan adsorption is shown in Fig. 4. It is observed from Figs. 4a and

$207 \mathrm{~b}$ that the equilibrium of ethanethiol adsorption attained within 420-480 min and 600 min for CSGAC and CSAC, respectively. The results demonstrate a faster adsorption rate of ethanethiol on CSGAC compared to that of CSAC. Concerning the 1-butanethiol, the adsorption equilibrium reached $720 \mathrm{~min}$ for CSAC and around 540-600 min for CSGAC, respectively. This phenomenon similarly indicates a higher removal efficiency of mercaptans using CSGAC. These outcomes could be resulted from the large porous channels

212 in a shell for CSGAC and in GAC-core. Furthermore, the removal rate of 1-butanethiol is slower than 213 ethanethiol by both adsorbents, which is likely due to the short-chain of ethanethiol molecular. This was 214 evidenced by (Barzamini et al., 2014), that the adsorption of mercaptans with long-chain would take a 215 longer time to enter into the pore of the adsorbent. Figs. $4 \mathrm{~b}$ and $\mathrm{c}$ illustrate the ethanethiol and 1-butanethiol 216 adsorption by PAC and PAC-core. As depicted in the figures, the equilibrium time for adsorption of these

217 two kinds of mercaptans by PAC and PAC-core is shorter than adsorption by CSAC. Moreover, in 
comparison to the adsorption rate of the ethanethiol and 1-butanethiol using PAC, the value by PAC-core

219 is slower. Likewise, the descending order of the mercaptans adsorption rate was GAC, GAC-core, and 220 CSGAC (Figs. 4e and f). This phenomenon could be explained by the mass transfer of ethanethiol and 1-

221 butanethiol molecular from the liquid phase to active sites of the AC-based adsorbents. With regards to the

222 CSAC or CSGAC, the shell would obstacle the mass transfer of molecules from the bulk solution to the

223 surface of adsorbents. Furthermore, the time for ethanethiol adsorption is shorter compared to that of the 1-

224 butanethiol. This outcome is attributed to the short-chain in ethanethiol as mentioned above, which is 225 beneficial for effective mass transfer. Nonetheless, mechanical strength is still an important issue to 226 guarantee real implementations of AC.

227 The kinetic parameters are shown in Table 3 and Table S1. According to the data, both the pseudo228 first-order and pseudo-second-order models are dominated on adsorption of ethanethiol by CSAC. 229 Nevertheless, the pseudo-second-order kinetic model describes better the sorption of ethanethiol by 230 CSGAC. With regards to 1-butanethiol, the pseudo-second-order kinetic model is better fitted to adsorption 231 processes by CSAC and CSGAC. According to the data of $\mathrm{R}^{2}$ in Table $\mathrm{S} 1$, the pseudo-second-order models 232 are dominated on adsorption of the mercaptans by PAC, PAC-core, GAC, and GAC-core. The intra-particle 233 diffusion is used to determine the diffusion process. According to the $\mathrm{R}^{2}$ values, the adsorption process is 234 not controlled by intra-particle diffusion.

\section{3.2.3. Effect of initial concentration}

236 Fig. 5 and Fig. S1 illustrate the effect of the initial concentration on the mercaptans adsorption by the 237 AC-based adsorbents. Figs. 5a and b show adsorption of the ethanethiol and 1-butanethiol by CSAC and 238 CSGAC under different initial concentrations, respectively. It can be seen from the figures that the 239 adsorption amount of the ethanethiol and 1-butanethiol increased as to increase the initial concentration. 240 The figures also illustrated that the removal efficiency for CSGAC is still higher compared to that of CSAC. 241 This phenomenon is attributed to the large intra-particles space in the shell and GAC-core for CSGAC. As 242 shown in Fig. S1, the ethanethiol and 1-butanethiol adsorption by PAC, GAC, PAC-core, and GAC-core 243 depicted similar trends with that of CSCA and CSGAC. This result is probably owing to the limited number 
of active sites on a constant amount of the adsorbents. Furthermore, adsorption isotherms of the ethanethiol and 1-butanethiol by CSAC and CSGAC were better fitted to the Langmuir model (Fig. 5c). The $\mathrm{q}_{\mathrm{m}}$ and $\mathrm{k}_{\mathrm{L}}$ are calculated according to the slope and intercept of a linear plot of $\mathrm{C}_{\mathrm{e}} / \mathrm{q}_{\mathrm{e}}$ against $\mathrm{C}_{\mathrm{e}}$, where the slope is 247 corresponding to $1 / \mathrm{q}_{\mathrm{m}}$ and intercept equals to $1 / \mathrm{q}_{\mathrm{m}} \mathrm{k}_{\mathrm{L}}$. The corresponding parameters were shown in Table

248 4. Likewise, the ethanethiol and 1-butanethiol adsorption using PAC, GAC, PAC-core, and GAC-core were 249 also better fitted to the Langmuir model (Table S1). This outcome indicates that the ethanethiol and 1butanethiol were removed by all of the AC-based adsorbents via monolayer adsorption. Accordingly, the ethanethiol and 1-butanethiol adsorption characteristics by CSAC and CSGAC were not changed after being protected by the shell. Furthermore, the adsorption capacities of ethanethiol and 1-butanethiol by CSAC were 139.28 and $125.63 \mu \mathrm{gS} \mathrm{g}{ }^{-1}$, respectively. And adsorption capacities of ethanethiol and 1butanethiol by CSGAC were 190.48 and $151.52 \mu \mathrm{gS} \mathrm{g}{ }^{-1}$, respectively. Additionally, 100 and 100\%, and 97.24 and $74.29 \%$ of ethanethiol and 1-butanethiol were removed by GAC-core and GAC, respectively. Hence, ethanethiol is more efficiently adsorbed compared to 1-butanethiol by the adsorbents. This is likely ascribed to the smaller resistance of mass transfer from shell to the surface of the AC core for short-chain ethanethiol. Furthermore, CSGAC exhibits a better adsorption performance to ethanethiol and 1-butanethiol than that of CSAC. This could have resulted from the larger intra-particles space of the shell and GAC core which is feasible for mercaptans molecular arriving at the GAC core and entrancing inner core. What's more, despite a better performance of the mercaptans removal using non-protected AC, the protected AC (CSAC and CSGAC) presented future promising of a good adsorbent for mercaptans removal from gasoline oil due to their good recovering and recycling.

\subsubsection{Influence of temperature and thermodynamic study}

The adsorption of ethanethiol and 1-butanethiol in the case of temperatures of $25,30,40$, and $60^{\circ} \mathrm{C}$ were further investigated (Fig. 6 and Fig. S2). It can be seen from the figures that the adsorption capacities

267 of ethanethiol and 1-butanethiol by most of the AC-based adsorbents increased as temperature increased.

268 This phenomenon is likely due to a decrease of the viscosity of the adsorbate solution as an increase in 269 temperature, leading to the improvement of the diffusion rate of adsorbate molecular through the external 
270 boundary layer to the internal pores of adsorbents (Meshkat et al., 2018a, 2018b). The results demonstrate

271 that $\mathrm{q}_{\mathrm{m}}$ increases as temperature elevates (Table 5), suggesting that a higher temperature promotes the 272 removal of mercaptans.

273 To better understand the effects of temperature, the thermodynamic parameters (Meshkat et al., 2018a,

274 2018b) were evaluated by Van't Hoff equations:

$275 \ln \left(\frac{\mathrm{q}_{\mathrm{e}}}{\mathrm{C}_{\mathrm{e}}}\right)=-\frac{\Delta \mathrm{H}^{\circ}}{\mathrm{RT}}+\frac{\Delta \mathrm{S}^{\circ}}{\mathrm{R}}$

$276\left(\Delta \mathrm{G}^{\circ}\right)=\Delta \mathrm{H}^{\circ}-\mathrm{T}\left(\Delta \mathrm{S}^{\circ}\right)$

277 where and $\mathrm{T}$ are presenting the universal gas constant $\left(8.314 \mathrm{~J} \mathrm{~mol}^{-1} \mathrm{~K}^{-1}\right)$ and the absolute temperature.

278 Plotting $\ln \left(\mathrm{q}_{\mathrm{e}} / \mathrm{C}_{\mathrm{e}}\right)$ versus $1 / \mathrm{T}$ shows a linear line with slope and intercept similar to $-\Delta \mathrm{H}^{\circ} / \mathrm{R}$ and $\Delta \mathrm{S}^{\circ} / \mathrm{R}$, 279 respectively (Figs. 7a-d).

280 The positive value of $\Delta \mathrm{H}^{\circ}$ in Table 6, Table S3, and Table S4 indicate that ethanethiol and 1-butanethiol 281 adsorption by CSAC, CSGAC, PAC-core, GAC, and GAC-core are endothermic processes. The data for 282 PAC, PAC-core, GAC, and GAC-core were presented in supporting information Table S3 and Table S4. 283 The negative value of $\Delta \mathrm{H}^{\circ}$ (Table S3) for PAC indicates that the process is exothermic. The Gibb free 284 energy of adsorption $\left(\Delta G^{\circ}\right)$ is estimated via Eq. 10. This negative data shows evidence of a spontaneous 285 adsorption reaction between adsorbents and ethanethiol and 1-butanethiol molecular. It is observed that the 286 heat from the physical adsorption falls into a range of $2.10-20.9 \mathrm{~kJ} \mathrm{~mol}^{-1}$, while the heat of chemisorption 287 locates at a range of $80-200 \mathrm{~kJ} \mathrm{~mol}^{-1}$. Both values are consistent with those of previous studies (Meshkat et 288 al., 2018a, 2018b).

\section{3.3. Adsorption competition}

Except for the ethanethiol and 1-butanethiol, 1-propanethiol was used as a coexisting organics to 291 investigate adsorption competence between these molecular by CSAC and CSGAC. In this study, the 292 solution of ethanethiol, 1-propanethiol, and 1-butanethiol with a concentration of $1000 \mathrm{ppb}$ in a bottle of $293100 \mathrm{~mL}$ was used to investigate the capability of the material in the competition of adsorption to different 294 kinds of mercaptans. Fig. 8 depicts that the ethanethiol is highly adsorbed while the 1-butanethiol is weakly 
removed by CSAC and CSGAC adsorbents, which is resulted from the short-chain of ethanethiol. The competition effect also was performed on PAC-based adsorbents and GAC-based adsorbents, the results

297 showed that ethanethiol is still highly removed compare to others and slightly affected by the competition

298 (Fig. 8). The reason is the same as mentioned above. For PAC-core and GAC-core presented high removal

299 efficiency for all adsorbents during the competition. This is attributed to the high active site generated to

300 the sintering of the sample at high temperatures. Conclusively, the increasing of the adsorption of mercaptans in multi pollutants environment will depend on the small molecular chain of mercaptans, the large intra-particles space of core-shell ACs, and high $\mathrm{S}_{\mathrm{BET}}$.

\subsection{The regeneration of CSGAC}

The regeneration process after the removal of mercaptans from gasoline oil was evaluated to confirm its re-usage and recyclability after the adsorption. As shown in Fig. 9a, the regenerated adsorbents still illustrate almost the same adsorption performance after regeneration of exhausted adsorbents six times. This result reveals a good regeneration performance and high stability of the CSGAC for mercaptans removal. Fig. 9b shows that the removal efficiency of PAC highly decreases after the regeneration at the fourth time compared to that of PAC-core. This is likely due to the more difficult recovering process compared to that of PAC-core. GAC-based adsorbents (GAC and GAC-core) showed a slightly shrinking recovered and also the small amount lost during recovering and recycling. In all, the original AC-based adsorbents and AC-core (PAC-core and GAC-core) presented a shrinking removal efficiency, whereas, the protected activated carbon-based adsorbents (CSAC and CSGAC) presented the constant removal 315 efficiency after six times of regeneration. This outcome evidences a promising application of protected 316 activated carbon-based adsorbents for mercaptans removal from the gasoline oil.

\section{3.5. The possible mechanisms of mercaptans adsorption by CSACs}

As illustrated in the previous study, the pore structure is a crucial factor to determine the mechanisms 
the shell to the external surface of the AC core and then continues to the inner core. As for CSGAC, features

322 such as the large intra-particles space between shell particles (Fig. 1c), broken pore structure (Fig. 1I), an 323 increasing of $\mathrm{S}_{\mathrm{BET}}$, micropore, and mesopores volumes of $\mathrm{AC}$ core after sintering at $1250^{\circ} \mathrm{C}$ (Table 2 ), are 324 advantageous for the removal of mercaptans into the pores of the GAC core.

Fig. 10 shows the TGA diagrams on saturated CSAC with mercaptans. Generally, the curves show an initial weight loss in the temperature range of $40-200^{\circ} \mathrm{C}$, which is the degradation of adsorbed mercaptans 327 and impurities. This phenomenon indicates clearly that mercaptans are fixed in the adsorbents. The mass 328 loss of the adsorbent is very insignificant because the adsorbents are sintered at high temperatures (Meshkat 329 et al., 2018a, 2018b).

Besides, the adsorption of ethanethiol and 1-butanethiol on CSAC or CSGAC was further confirmed by elemental analysis (Table 7). As shown in the table, the number of sulfur increased after the adsorption of sulfide compounds on core-shell AC adsorbents. These results further prove the existence of mercaptan molecular on the surface of adsorbents surface.

Furthermore, the FTIR analysis (Fig. 11) was performed to detect the adsorption of mercaptans by CSACs. According to the previous work (Cheng et al., 2020; Meshkat et al., 2018b; Pham et al., 2013), the new peaks between 1155 to $600 \mathrm{~cm}^{-1}$ could be corresponding to the bond between $\mathrm{C}$ and $\mathrm{S}$. Although no new peak appeared after adsorption of ethanethiol on CSGAC, the result indicates the appearance of the new peaks after adsorption of 1-butanethiol and ethanethiol by CSAC and CSGAC.

Conclusively, the results provided by TG, elemental analysis, and FTIR after adsorption, consistently state clear that the mercaptans molecular are adsorbed on the core-shell structured AC composites. The Van der Waals forces, electron donor-acceptor interactions, and chemical affinity are responsible for the 342 adsorption of the mercaptans (Dehghan and Anbia, 2017). The high mercaptan removal efficiency of 343 adsorbent requires a large size and high dipole moment of mercaptan, which is attracted to adsorbent with 344 strong Van der Waals (Meshkat et al., 2018b). The electron donor-acceptor interactions between the S 345 atoms and the basic adsorbent, the dispersion effect between the mercaptans molecular and the $\pi$-electrons 346 of the carbon adsorbent are two important factors. The energetic heterogeneity is caused by the connectivity, 

such as the Van der Waals force, $\pi-\pi$ dispersion interaction, and hydrophobic compatibility of mercaptans molecular with the surface of the adsorbent, mercaptans molecular could be efficiently removed from the 350 fuel.

\section{Conclusions}

The mercaptans from the gasoline oil are efficiently removed by core-shell AC-based Adsorbents (CSAC and CSGAC). The protected ACs are future good adsorbent as presented the good recovering and recycling after adsorption of mercaptans. The large intra-particles space in both the shell and AC are advantageous of good adsorption performance of CSGAC compared to that of CSAC. Although the PAC, PAC-core, and GAC-core presented high performance compared to their protected forms, their adsorption capacity was shrunk after the regeneration due to their low recovering and recycling after adsorption. The mercaptan adsorption by core-shell AC adsorbents was more precisely fitted to Langmuir isotherm than the Freundlich model. The capacity of Ethanethiol and 1-Butanethiol by CSGAC adsorption are 190.48 and 151.52 $\mu \mathrm{gS} \mathrm{g}^{-1}$, respectively. The mercaptan adsorption by core-shell AC adsorbents is proven to be an endothermic and spontaneous process. The core-shell AC materials are also proved with good recyclability and regeneration at $600^{\circ} \mathrm{C}$. The possible mechanisms of the adsorption on CSGAC simultaneously depend on Vander Waal's force, pore texture, $\pi-\pi$ dispersion interaction, and hydrophobic properties of mercaptan molecules.

\section{Acknowledgments}

The Authors acknowledged, the Strategic Priority Research Program of the Chinese Academy of Sciences [Grant No. XDA23030301, XDA23020504], the Special Research Assistant Program of the Chinese Academy of Sciences, the Science and Technology program of Xiamen (Grant No. 3502Z20203075, 3502Z20203074), as well as CAS-TWAS President's Fellowship Program. 
375 This manuscript is original not submitted to other journals nor published elsewhere. The work was not split

376 into many parts presented, and there is no fabrication, falsification or inappropriate data manipulation. This

377 work has no plagiarism, and the similarities have been decreased to under $25 \%$ and proper 378 acknowledgement was given.

\section{Consent to Participate}

380 All authors participated in this work as shown in the statement of Authors contribution.

Consent to Publish

382 All Authors confirmed that the work has not been published before and it is not under consideration for 383 publication elsewhere.

\section{Authors Contributions}

385 Pamphile Ndagijimana, his contribution focused on doing experiment and writing the manuscript.

386 Xuejiao Liu contributed in guiding, revising the manuscript and funding the work.

387 Zhiwei Li, Zhenjiao Xing, Beibei Pan, and Guangwei Yu revised this manuscript.

388 Yin Wang also contributed in guiding, revising the manuscript and funding the work.

\section{Funding}

390 This work was funded by the Strategic Priority Research Program of the Chinese Academy of Sciences 391 [Grant No. XDA23030301, XDA23020504], the Special Research Assistant Program of the Chinese 392 Academy of Sciences, and the Science and Technology program of Xiamen (Grant No. 3502Z20203075, 393 3502Z20203074), as well as CAS-TWAS President's Fellowship Program. 


\section{Competing Interests}

396 All authors declared that this work has no conflict of Interest. Availability of data and materials

398 Regarding the data and material in this manuscript, all authors concluded that, the data available online

399 (DOI link provided by Journal after publication) will be shared according to the requirement of this

400 Journal.

401 


\section{References}

Aguiar M F de, Coelho GLV (2017) Adsorption of sulfur compounds from natural gas by different adsorbents and desorption using supercritical $\mathrm{CO}_{2} . \quad$ J. Environ. Chem. Eng. 5, 4353-4364. https://doi.org/https://doi.org/10.1016/j.jece.2017.07.079

Barzamini R, Falamaki C, Mahmoudi R (2014) Adsorption of ethyl, iso-propyl, n-butyl, and iso-butyl mercaptans on $\operatorname{AgX}$ zeolite: Equilibrium and kinetic study. Fuel 130, 46-53. https://doi.org/https://doi.org/10.1016/j.fuel.2014.04.013

Bashkova S, Bagreev A, Bandosz TJ (2002) Adsorption of Methyl Mercaptan on Activated Carbons. Environ. Sci. I\& Technol. 36, 2777-2782. https://doi.org/10.1021/es011416v

Cheng L, Guan K, Liu G, Jin W (2020) Cysteamine-crosslinked graphene oxide membrane with enhanced hydrogen separation property. J. Memb. Sci. 595, 117568. https://doi.org/https://doi.org/10.1016/j.memsci.2019.117568

Daraee M, Saeedirad R, Ghasemy E, Rashidi A (2021) N-CNT/ZIF-8 nano-adsorbent for adsorptive desulfurization of the liquid streams: Experimental and. J. Environ. Chem. Eng. 9, 104806. https://doi.org/https://doi.org/10.1016/j.jece.2020.104806

Dehghan R, Anbia M (2017) Zeolites for adsorptive desulfurization from fuels: A review. Fuel Process. Technol. 167, 99-116. https://doi.org/https://doi.org/10.1016/j.fuproc.2017.06.015

Fan Y, Shi G, Bao X (2013) A process for producing ultraclean gasoline by coupling efficient hydrodesulfurization and directional olefin conversion. AIChE J. 59, 571-581. https://doi.org/https://doi.org/10.1002/aic.13832

Farzin Nejad N, Miran Beigi A A (2015) Efficient desulfurization of gasoline fuel using ionic liquid extraction as a complementary process to adsorptive desulfurization. Pet. Sci. 12, 330-339. https://doi.org/10.1007/s12182015-0020-2

Gao L, Xue Q, Liu Y, Lu Y, (2009) Base-free catalytic aerobic oxidation of mercaptans for gasoline sweetening over HTLcs-derived CuZnAl catalyst. AIChE J. 55, 3214-3220. https://doi.org/https://doi.org/10.1002/aic.11928

Huang T, Peng Q, Shi W, Xu J, Fan Y (2018) An anionic surfactant-assisted equilibrium adsorption method to prepare highly dispersed Fe-promoted $\mathrm{Ni} / \mathrm{Al}_{2} \mathrm{O}_{3}$ catalysts for highly selective mercaptan removal. Appl. Catal. B 
Koncsag C I, Barbulescu A (2008) Modelling the removal of mercaptans from liquid hydrocarbon streams in structured packing columns. Chem. Eng. Process. Process Intensif. 47, 1717-1725. https://doi.org/https://doi.org/10.1016/j.cep.2007.09.015

Lee S W, Daud W M A W, Lee M G (2010) Adsorption characteristics of methyl mercaptan, dimethyl disulfide, and trimethylamine on coconut-based activated carbons modified with acid and base. J. Ind. Eng. Chem. 16, 973977. https://doi.org/https://doi.org/10.1016/j.jiec.2010.04.002

Liu X, Lai D, Wang Y (2019) Performance of Pb (II) removal by an activated carbon supported nanoscale zero-valent iron composite at ultralow iron content. J. Hazard. Mater. 361, 37-48. https://doi.org/10.1016/j.jhazmat.2018.08.082

Mahmoudabadi ZS, Tavasoli A, Rashidi A. et al (2021) Catalytic activity of synthesized 2D MoS2/graphene

Meshkat S S, Rashidi A, Tavakoli O (2018a) Removal of mercaptan from natural gas condensate using N-doped nanohybrids for the hydrodesulfurization of SRLGO: experimental and DFT study. Environ Sci Pollut Res 28, 5978-5990. https://doi.org/10.1007/s11356-020-10889-8

443 carbon nanotube adsorbents: Kinetic and DFT study. J. Nat. Gas Sci. Eng. 55, $288-297$. https://doi.org/https://doi.org/10.1016/j.jngse.2018.04.036

Meshkat S S, Tavakoli O, Rashidi A, Esrafili M D (2018b) Adsorptive mercaptan removal of liquid phase using nanoporous graphene: Equilibrium, kinetic study and DFT calculations. Ecotoxicol. Environ. Saf. 165, 533-539. https://doi.org/https://doi.org/10.1016/j.ecoenv.2018.08.110

Mguni L L, Yao Y, Liu X, Yuan Z, Hildebrandt D (2019) Ultra-deep desulphurization of both model and commercial diesel fuels by adsorption method. J. Environ. Chem. Eng. 7, 102957. https://doi.org/https://doi.org/10.1016/j.jece.2019.102957

Mohebbi A, Mohebbi V, (2017) Equilibrium adsorption of ethyl mercaptan and thiophene using molecular sieve 13X. Fluid Phase Equilib. 436, 30-37. https://doi.org/https://doi.org/10.1016/j.fluid.2016.12.023 

https://doi.org/https://doi.org/10.1016/j.scitotenv.2019.06.235

454 455

456

457 458

471

Ndagijimana P, Liu X, Yu G, Wang Y(2019a) Synthesis of a novel core-shell-structure activated carbon material and its application in sulfamethoxazole adsorption. J. Hazard. Mater. 368, 602-612. https://doi.org/https://doi.org/10.1016/j.jhazmat.2019.01.093

Ndagijimana, P, Liu X, Li Z, Yu G, Wang Y (2020) The synthesis strategy to enhance the performance and cyclic utilization of granulated activated carbon-based sorbent for bisphenol A and triclosan removal. Environ. Sci. Pollut. Res. 27, 15758-15771. https://doi.org/10.1007/s11356-020-08095-7

Pham C V, Eck M, Krueger M (2013) Thiol functionalized reduced graphene oxide as a base material for novel graphene-nanoparticle hybrid composites. Chem. Eng. J. 231, 146-154. https://doi.org/https://doi.org/10.1016/j.cej.2013.07.007

Rodríguez-Cabo B, Rodríguez H, Rodil E, Arce A, Soto A (2014) Extractive and oxidative-extractive desulfurization of fuels with ionic liquids. Fuel 117, 882-889. https://doi.org/https://doi.org/10.1016/j.fuel.2013.10.012

SHEN Y, SHUAI S, WANG J, XIAO J (2009) Optimization of gasoline hydrocarbon compositions for reducing exhaust emissions. J. Environ. Sci. 21, 1208-1213. https://doi.org/https://doi.org/10.1016/S10010742(08)62405-5

Shiraishi Y, Tachibana K, Hirai T, Komasawa I (2002) Desulfurization and Denitrogenation Process for Light Oils Based on Chemical Oxidation followed by Liquid-Liquid Extraction. Ind. I\& Eng. Chem. Res. 41, 4362-4375. https://doi.org/10.1021/ie010618x

Srivastava VC (2012) An evaluation of desulfurization technologies for sulfur removal from liquid fuels 759-783. https://doi.org/10.1039/c1ra00309g

Sun H, Han X, Liu K, Shen B, Liu J, Wu D, Shi X (2017) Metal-Modified Cu-BTC Acid for Highly Enhanced Adsorption of Organosulfur Species. Ind. I\& Eng. Chem. Res. 56, 9541-9550. https://doi.org/10.1021/acs.iecr.7b02392

Wang S, Fan Y, Jia X (2014) Sodium dodecyl sulfate-assisted synthesis of hierarchically porous ZIF-8 particles for 
477

478

479

480

481

482

483

484

485

486

487

488

489

490

491

492

493

494

495

496

removing mercaptan from gasoline. Chem. Eng. J. 256, 14-22. https://doi.org/https://doi.org/10.1016/j.cej.2014.06.095

Zhang Y, Liu Z, Wang W, Cheng Z, Shen B( 2013) Research on the MgO-supported solid-base catalysts aimed at the sweetening of hydrogenated gasoline. Fuel Process. Technol. 115, 63-70. https://doi.org/https://doi.org/10.1016/j.fuproc.2013.03.046

列

3

4

5

86


Table 1. Physicochemical properties of mercaptans

\begin{tabular}{|c|c|c|c|c|c|}
\hline Pollutants & Formula & Structure & Water solubility & $\log K_{\text {ow }}$ & $\mathrm{pK}_{\mathrm{a}}$ \\
\hline Ethanethiol & $\mathrm{C}_{2} \mathrm{H}_{6} \mathrm{~S}$ & & $8.86 \mathrm{~g} / \mathrm{L}$ at $20^{\circ} \mathrm{C}$ & 1.50 & 10.60 \\
\hline 1-Butanethiol & $\mathrm{C}_{4} \mathrm{H}_{10} \mathrm{~S}$ & & $0.06 \%$ & 2.28 & -10.78 \\
\hline
\end{tabular}

497

498

499

500

501

502

503

504

505

506

507

508

509

510

511

512 
Table. 2. Surface area, pore-volume, and pore size of used carbon-based adsorbents

\begin{tabular}{cccc}
\hline Sample & Surface area $\left(\mathrm{m}^{2} \mathrm{~g}^{-1}\right)$ & Pore volume $\left(\mathrm{cm}^{3} \mathrm{~g}^{-1}\right)$ & Pore size $(\mathrm{nm})$ \\
\hline PAC & 823.00 & 0.44 & 2.15 \\
PAC-core & 1095.00 & 0.59 & 2.16 \\
CSAC & 199.00 & 0.11 & 2.50 \\
GAC & 509.78 & 0.28 & 2.20 \\
GAC-core & 978.95 & 0.54 & 2.60 \\
CSGAC & 141.79 & 0.06 & 3.00 \\
\hline
\end{tabular}

514

515

516

517

518

519

520

521

522

523

524

525

526

527 
Table 3. Kinetics study of Mercaptans adsorption by CSAC and CSGAC

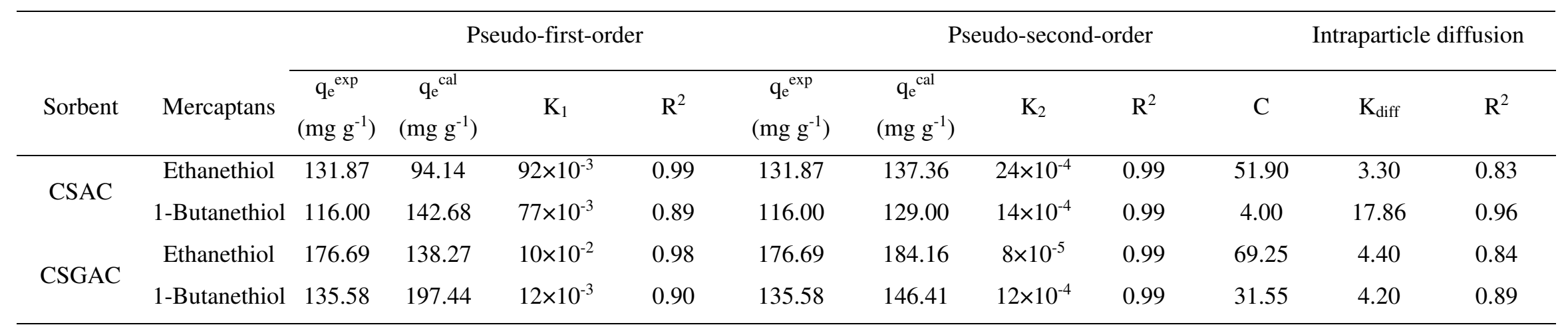

529

530

531

532

533

534 
Table 4. The isotherm parameters of mercaptans adsorption by CSAC and CSGAC

\begin{tabular}{ccccc}
\hline Sorbents & Sorbates & \multicolumn{3}{c}{ Langmuir isotherm } \\
\hline \multirow{3}{*}{ CSAC } & Ethanethiol & 139.28 & $1.8 \times 10^{-3}$ & 0.999 \\
\cline { 3 - 5 } & 1-Butanethiol & 125.63 & $79 \times 10^{-3}$ & 0.998 \\
\multirow{2}{*}{ CSGAC } & Ethanethiol & 190.48 & $10 \times 10^{-3}$ & 0.999 \\
& 1-Butanethiol & 151.52 & $66 \times 10^{-3}$ & 0.999 \\
\hline
\end{tabular}

538

539

540

541

542

543

544

545

546

547

548

549

550 
Table 5. Langmuir parameters as functions of mercaptan molecule and temperature on core-shell ACs

\begin{tabular}{cccccc}
\hline Adsorbents & Mercaptans & Temperature $\left({ }^{\circ} \mathrm{C}\right)$ & $\mathrm{q}_{\mathrm{m}}\left(\mathrm{mgS} \mathrm{g}^{-1}\right)$ & $\mathrm{b}\left(\mathrm{mgS} \mathrm{L}^{-1}\right)$ & $\mathrm{R}^{2}$ \\
\hline CSAC & Ethanethiol & 25 & 139.28 & $18 \times 10^{-3}$ & 0.999 \\
CSAC & Ethanethiol & 30 & 139.86 & $17 \times 10^{-3}$ & 0.999 \\
CSAC & Ethanethiol & 40 & 141.84 & $15 \times 10^{-3}$ & 0.999 \\
CSAC & Ethanethiol & 60 & 142.86 & $13 \times 10^{-3}$ & 0.999 \\
CSAC & 1-Butanethiol & 25 & 125.60 & $37 \times 10^{-3}$ & 0.998 \\
CSAC & 1-Butanethiol & 30 & 128.87 & $39 \times 10^{-3}$ & 0.999 \\
CSAC & 1-Butanethiol & 40 & 132.45 & $37 \times 10^{-3}$ & 0.999 \\
CSAC & 1-Butanethiol & 60 & 135.67 & $33 \times 10^{-3}$ & 0.999 \\
CSGAC & Ethanethiol & 25 & 190.48 & $10 \times 10^{-3}$ & 0.999 \\
CSGAC & Ethanethiol & 30 & 196.08 & $11 \times 10^{-4}$ & 0.999 \\
CSGAC & Ethanethiol & 40 & 202.83 & $10 \times 10^{-4}$ & 0.999 \\
CSGAC & Ethanethiol & 60 & 206.00 & $49 \times 10^{-5}$ & 0.999 \\
CSGAC & 1-Butanethiol & 25 & 151.5 & $18 \times 10^{-3}$ & 0.999 \\
CSGAC & 1-Butanethiol & 30 & 155.8 & $19 \times 10^{-3}$ & 0.999 \\
CSGAC & 1-Butanethiol & 40 & 157.73 & $16 \times 10^{-3}$ & 0.999 \\
CSGAC & 1-Butanethiol & 60 & 169.21 & $87 \times 10^{-4}$ & 0.999 \\
\hline
\end{tabular}

551

552

553

554

555

556

557

558

559

560 
Table 6. Thermodynamic study of core-shell ACs

\begin{tabular}{|c|c|c|c|c|c|c|c|c|}
\hline \multirow[t]{2}{*}{ Adsorbents } & \multirow[t]{2}{*}{ Adsorbate } & \multirow[t]{2}{*}{$\begin{array}{c}\mathrm{C}_{0} \\
\left(\mathrm{mg} \mathrm{S} \mathrm{L}^{-1}\right)\end{array}$} & \multirow[t]{2}{*}{$\begin{array}{c}\Delta \mathrm{H} \\
\left(\mathrm{kJ} \mathrm{mol}^{-1}\right)\end{array}$} & \multirow[t]{2}{*}{$\begin{array}{c}\Delta \mathrm{S} \\
\left(\mathrm{J} \mathrm{mol}^{-1} \mathrm{~K}^{-1}\right)\end{array}$} & \multicolumn{4}{|c|}{$\Delta \mathrm{G}\left(\mathrm{kJ} \mathrm{mol}^{-1}\right)$} \\
\hline & & & & & $298 \mathrm{~K}$ & $303 \mathrm{~K}$ & $313 \mathrm{~K}$ & $333 \mathrm{~K}$ \\
\hline CSAC & Ethanethiol & 800 & 2.37 & 1.98 & 1.79 & 1.78 & 1.71 & 1.73 \\
\hline CSAC & Ethanethiol & 900 & 1.44 & -2.03 & 2.04 & 2.43 & 2.82 & 2.11 \\
\hline CSAC & Ethanethiol & 1000 & 3.23 & 2.04 & 2.68 & 2.58 & 2.51 & 2.59 \\
\hline CSAC & Ethanethiol & 1200 & 3.92 & 0.85 & 3.67 & 3.65 & 3.66 & 3.63 \\
\hline CSAC & Ethanethiol & 1500 & 2.73 & -6.35 & 4.59 & 4.67 & 4.76 & 4.83 \\
\hline CSAC & Ethanethiol & 2000 & 2.99 & -9.18 & 5.69 & 5.79 & 5.91 & 6.03 \\
\hline CSAC & $\begin{array}{c}1- \\
\text { Butanethiol }\end{array}$ & 800 & 3.33 & 1.41 & 2.89 & 2.93 & 2.91 & 2.85 \\
\hline CSAC & $\begin{array}{c}1- \\
\text { Butanethiol }\end{array}$ & 900 & 4.05 & 2.81 & 3.21 & 3.24 & 3.21 & 3.12 \\
\hline CSAC & $\begin{array}{c}1- \\
\text { Butanethiol }\end{array}$ & 1000 & 3.71 & 1.32 & 3.32 & 3.27 & 3.35 & 3.25 \\
\hline CSAC & $\begin{array}{c}1- \\
\text { Butanethiol }\end{array}$ & 1200 & 2.69 & -4.78 & 4.16 & 4.14 & 4.13 & 4.33 \\
\hline CSAC & $\begin{array}{c}1- \\
\text { Butanethiol }\end{array}$ & 1500 & 2.52 & -8.52 & 5.17 & 5.17 & 5.13 & 5.38 \\
\hline CSAC & 1-Butanethiol & 2000 & 2.49 & -12.16 & 6.13 & 6.16 & 6.28 & 6.55 \\
\hline CSGAC & Ethanethiol & 800 & - & - & - & - & - & - \\
\hline CSGAC & Ethanethiol & 900 & 515.67 & 1779 & -14.4 & -23.3 & - & - \\
\hline CSGAC & Ethanethiol & 1000 & 35.27 & 137.76 & -5.4 & -7.0 & -7.7 & - \\
\hline CSGAC & Ethanethiol & 1200 & 12.93 & 43.38 & 0.079 & -0.24 & -0.73 & -1.5 \\
\hline CSGAC & Ethanethiol & 1500 & 8.05 & 19.41 & 2.27 & 2.19 & 1.93 & 1.61 \\
\hline CSGAC & Ethanethiol & 2000 & 3.87 & 0.059 & 3.93 & 383 & 3.76 & 3.91 \\
\hline CSGAC & 1-Butanethiol & 800 & 12.72 & 39.14 & 0.91 & 0.91 & 0.68 & -0.42 \\
\hline CSGAC & 1-Butanethiol & 900 & 13.20 & 39.89 & 1.14 & 1.14 & 1.02 & -0.23 \\
\hline CSGAC & 1-Butanethiol & 1000 & 12.11 & 35.41 & 1.43 & 1.38 & 1.27 & 0.21 \\
\hline CSGAC & 1-Butanethiol & 1200 & 12.76 & 33.09 & 2.74 & 2.69 & 2.50 & 1.61 \\
\hline CSGAC & 1-Butanethiol & 1500 & 8.23 & 14.09 & 3.99 & 3.97 & 3.86 & 3.51 \\
\hline CSGAC & 1-Butanethiol & 2000 & 4.75 & -1.62 & 5.17 & 5.16 & 5.28 & 5.21 \\
\hline
\end{tabular}


Table 7. The elemental analysis of pristine and treated CSAC and CSGAC

\begin{tabular}{cccc}
\hline Elements & $\mathrm{N}$ & $\mathrm{C}$ & $\mathrm{S}$ \\
\hline CSAC $^{\mathrm{a}}$ & 0.083 & 12.00 & 0.041 \\
CSGAC $^{\mathrm{a}}$ & 0.018 & 11.11 & 0.042 \\
CSAC $^{\mathrm{b}}$ & 0.055 & 35.51 & 0.41 \\
CSGAC $^{\mathrm{b}}$ & 0.044 & 29.93 & 0.65 \\
\hline
\end{tabular}

$564 \quad{ }^{\mathrm{a} B e f o r e}$ adsorption

$565 \quad{ }^{b}$ After adsorption

566

567

568

569

570

571

572

573

574

575

576

577

578

579 
582 Fig. 1. SEM images of shell (a), intra-particle space or void in shell of CSAC (b), CSGAC (c), physical images 583 of CSAC (d), CSGAC (e), GAC-core (f), PAC-core (g), SEM images of PAC-core (h), and GAC-core (i).

584 Fig. 2. The pore distribution of PAC-based adsorbent (a), GAC-based adsorbent (b), and core-shell ACs (c, d).

Fig. 3. Effect of adsorbent dosage on the mercaptans removal by CSAC and CSGAC (a), PAC-based adsorbents (b), and GAC-based adsorbents(c). (Conditions: $\mathrm{C}_{0}=2000 \mathrm{ppm}, \mathrm{V}=50 \mathrm{~mL}$, mass $=0.24 \mathrm{~g}$ (CSAC), $0.28 \mathrm{~g}$ (CSGAC), $0.05 \mathrm{~g}$ (PAC-core and PAC), and $0.03 \mathrm{~g}$ (GAC-core and GAC)).

Fig. 4. Effect of contact time for CSAC and CSGAC (a, b) and for PAC, PAC-core, GAC, GAC-core (c-f). (Conditions: $\mathrm{C}_{0}=1000 \mathrm{ppm}, \mathrm{V}=50 \mathrm{~mL}$, mass $=0.24 \mathrm{~g}(\mathrm{CSAC}), 0.28 \mathrm{~g}(\mathrm{CSGAC}), 0.05 \mathrm{~g}$ (PAC-core and PAC) and $0.03 \mathrm{~g}$ (GAC-core and GAC).

Fig. 5. Effect of initial concentration on mercaptans removal (a, b), and Langmuir fitting model (c)

Fig. 6. Temperature effect: Ethanethiol adsorbed on CSAC and CSGAC (a, b), 1-Butanethiol adsorbed on CSAC and CSGAC (c, d).

Fig. 7. The plot of $K_{C}$ versus $1 / T$ for determination of mercaptans removal reaction enthalpy.

Fig. 8. Adsorption competition of mercaptans by core- shell ACs, PAC-based adsorbents and GAC-based adsorbents. (Conditions: $\mathrm{C}_{0}=1000 \mathrm{ppm}, \mathrm{V}=50 \mathrm{~mL}$, mass $=0.24 \mathrm{~g}$ (CSAC), $0.28 \mathrm{~g}$ (CSGAC), $0.05 \mathrm{~g}$ (PAC-core and PAC) and $0.03 \mathrm{~g}$ (GAC-core and GAC).

Fig. 9. Thermal regeneration of mercaptans by core-shell AC (a) and PAC and GAC based adsorbents (b, c).

Fig. 10. TG and DTG curves of treated CSAC and CSGAC.

Fig. 11. FTIR spectra of pristine and treated CSAC and CSGAC. 
604

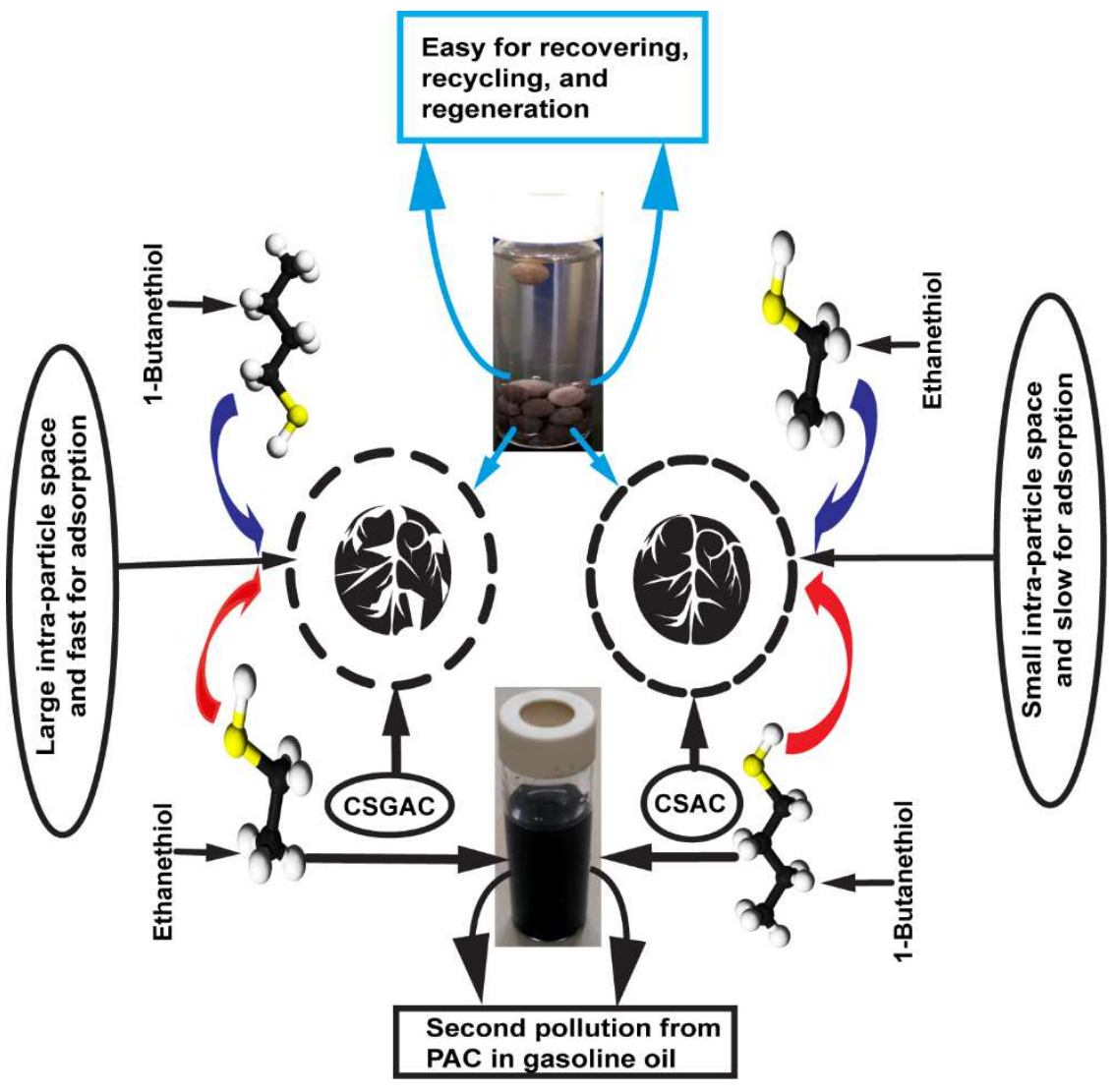

606

607

608

609

610 
618
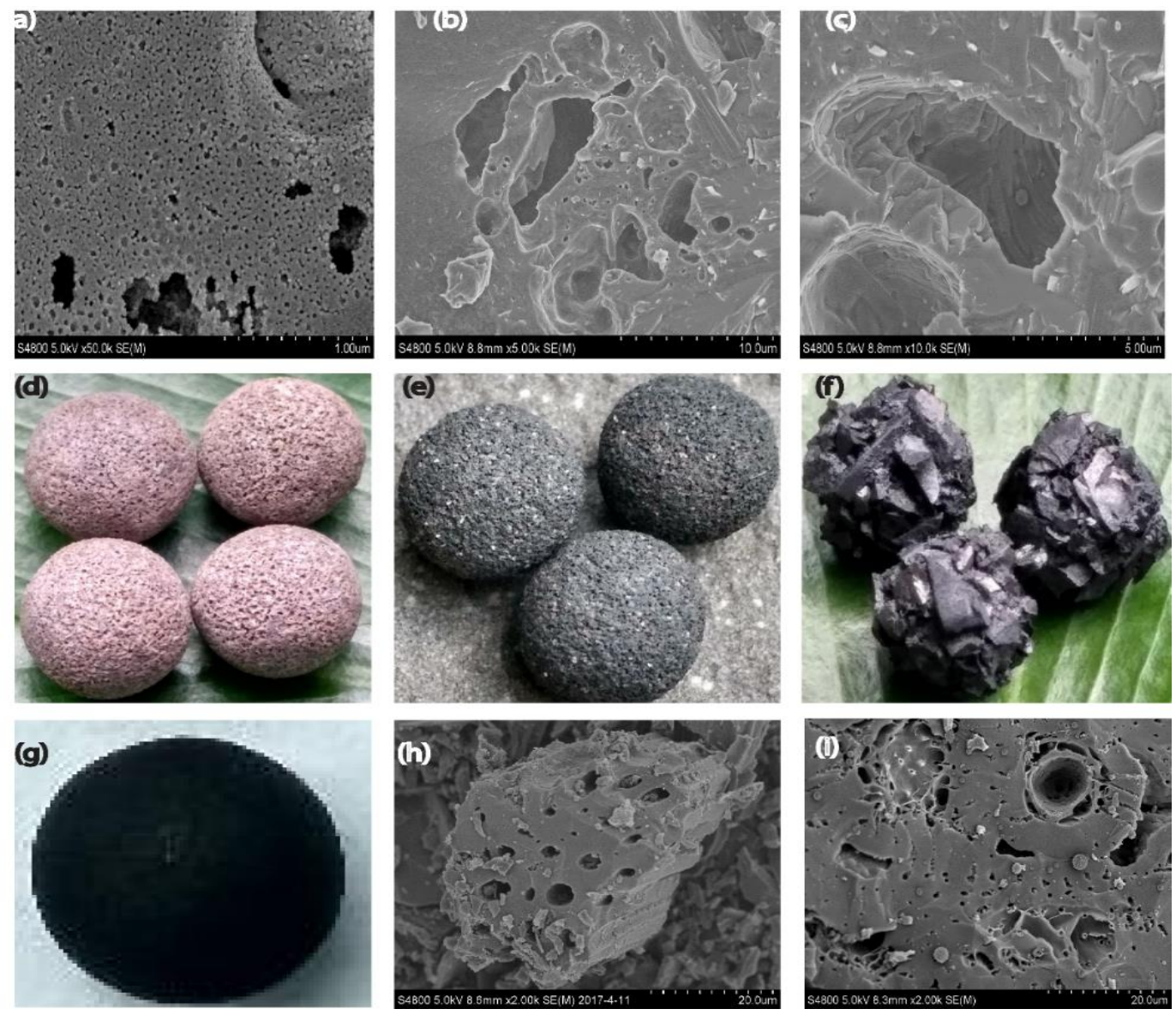

Fig. 1. 

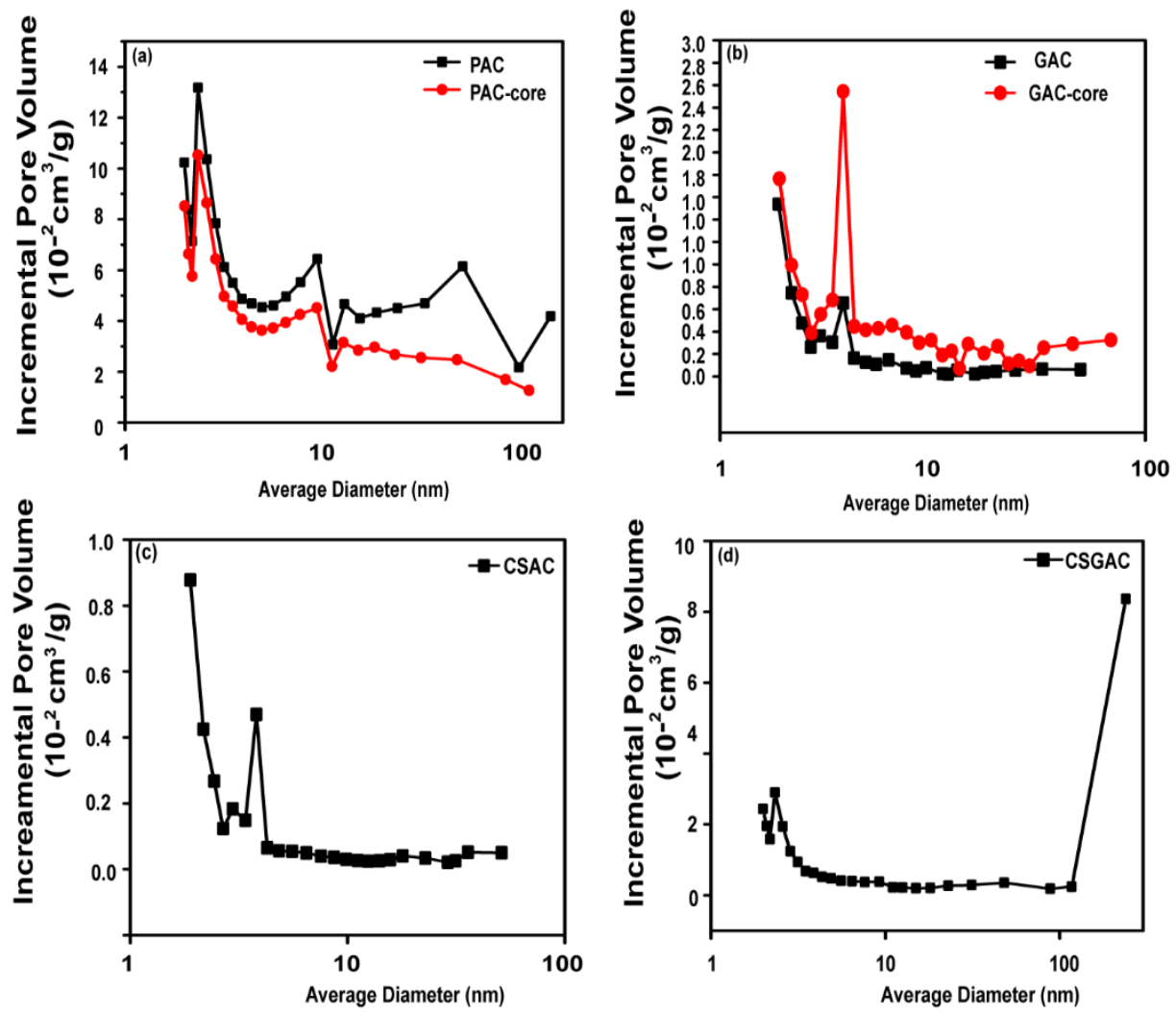

628

Fig. 2.

629

630

631

632

633

634

635

636

637 
- Ethanethiol adsorbed on CSAC

-1-Butanethiol adsorbed on CSAC

- Ethanethiol adsorbed on CSGAC

1- Butanethiol adsorbed on CSGAC

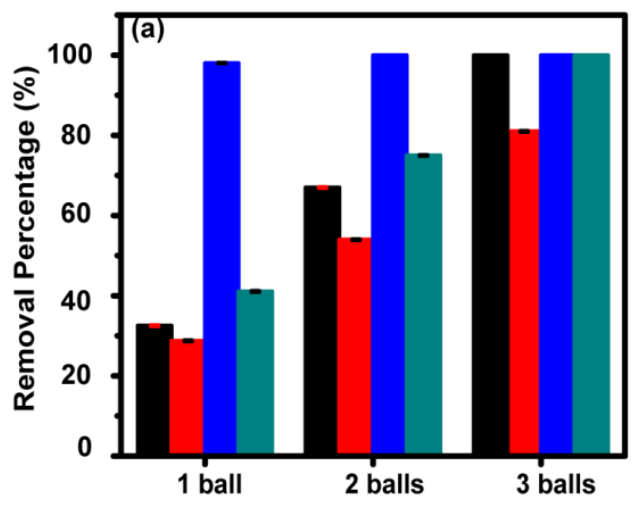

- Ethanethiol adsorbed on PAC

- 1- Butanethiol adsorbed on PAC

- Ethanethiol adsorbed on PAC-core

-1-Butanethiol adsorbed on PAC-core

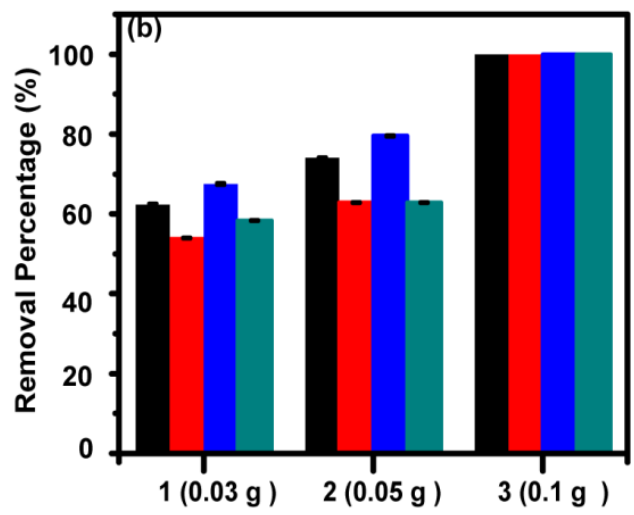

Ethanethiol adsorbed on GAC

1- Butanethiol adsorbed on GAC

- Ethanethiol adsorbed on GAC-core

-1-Butanethiol adsorbed on GAC-core

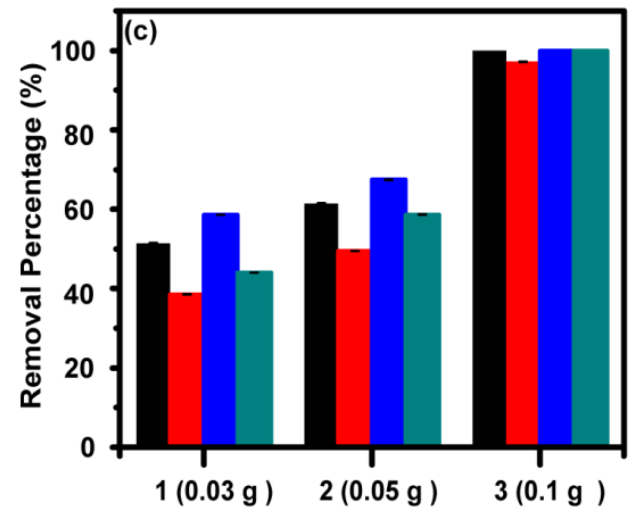

Fig. 3. 
- $R_{e}$ Ethanethiol $\square-q_{t}$ Ethanethiol

- $R_{\mathrm{e}}$ 1-Butanethiol $\square \mathrm{q}_{\mathrm{t}}$ 1-Butanethiol

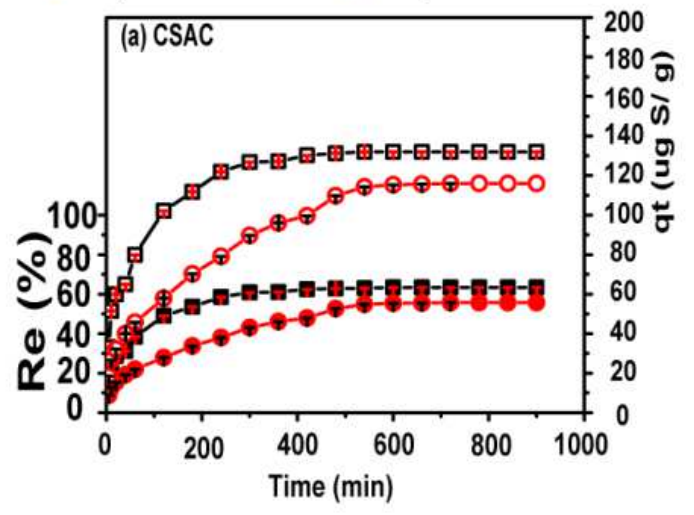

- $R_{e}$ Ethanethiol $\square-q_{t}$ Ethanethiol

- $R_{e}$ 1-Butanethiol $\square-q_{t}$ 1-Butanethiol

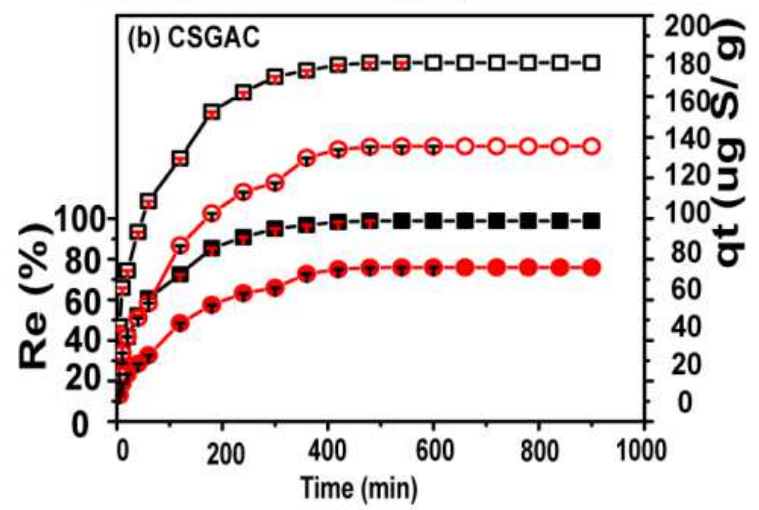

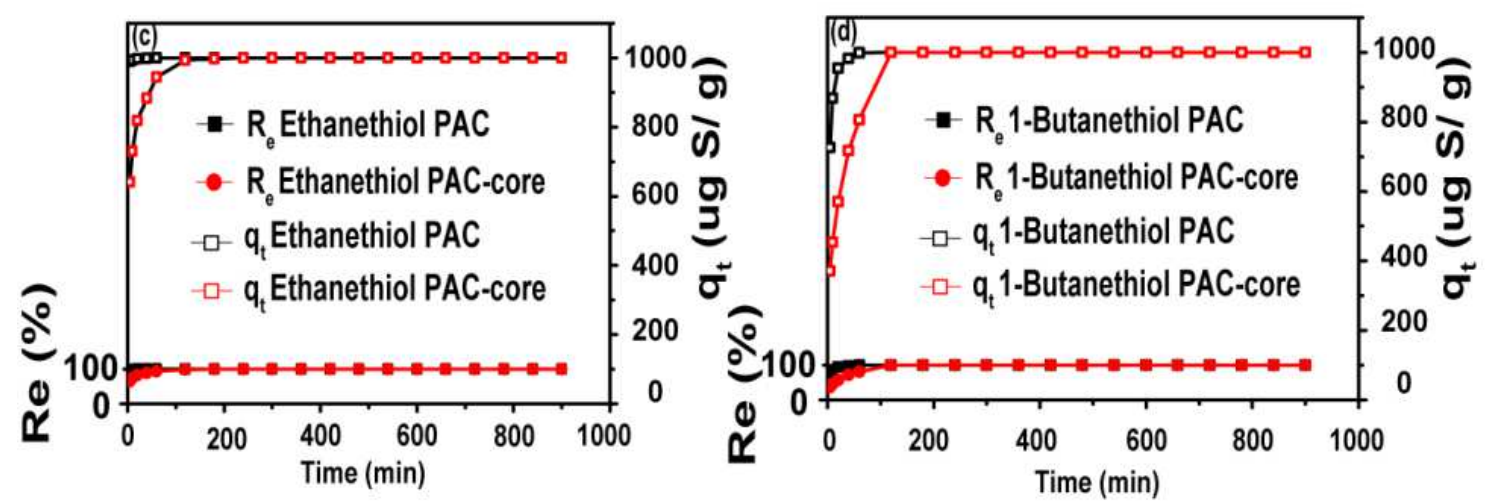



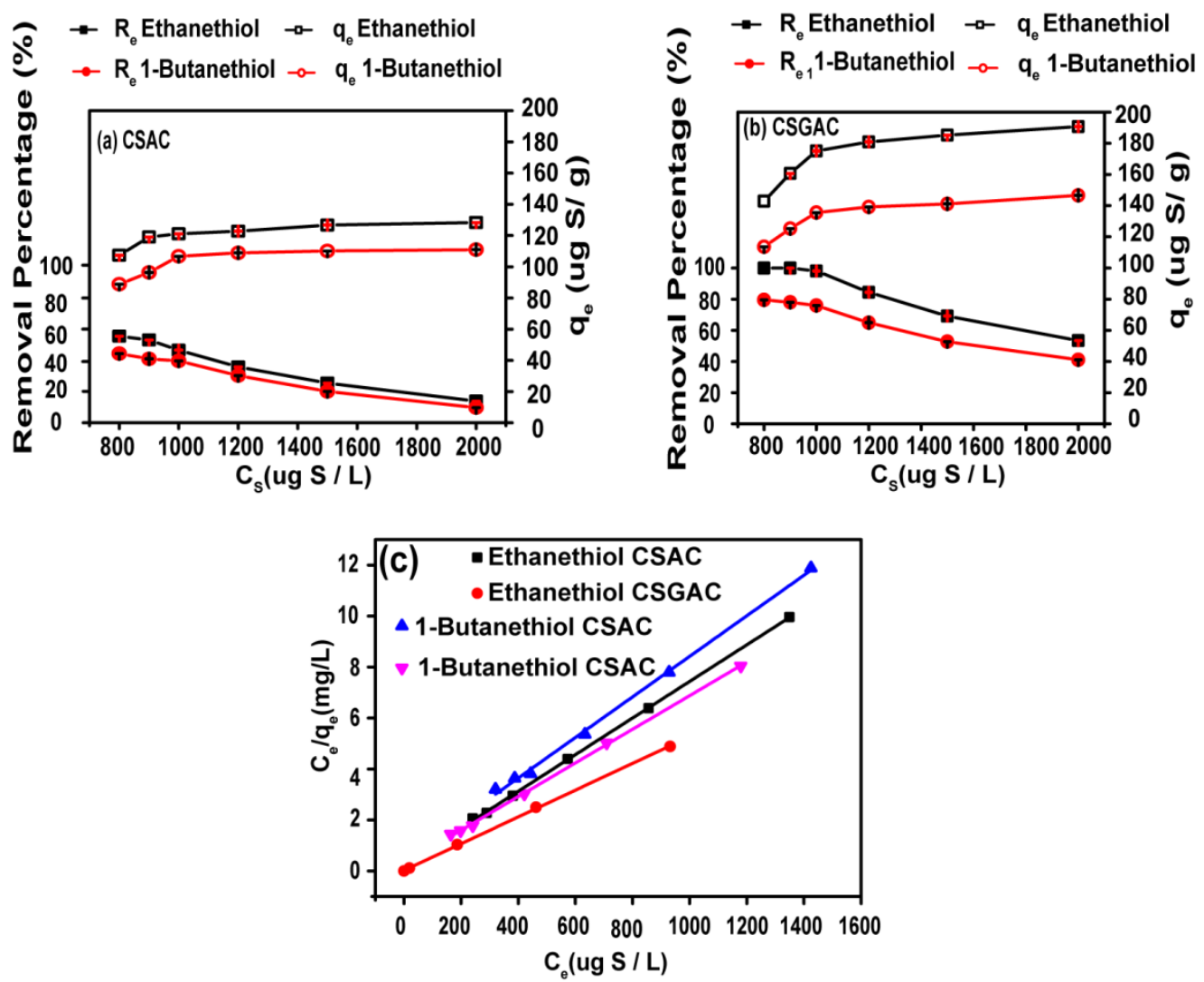

Fig. 5.

654

655

656

657

658

659 

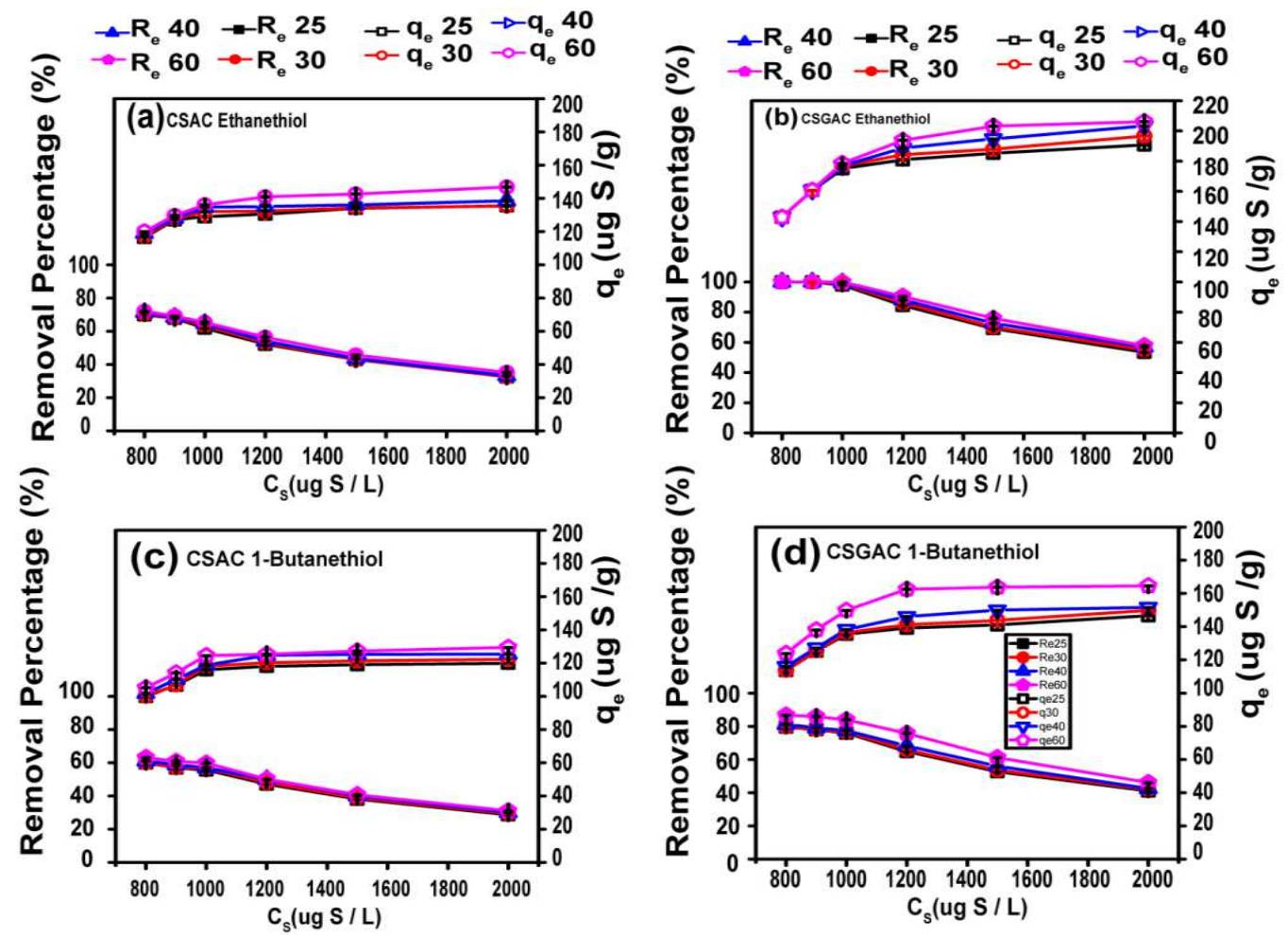

Fig. 6.

663

664

665

666

667

668

669

670

671 

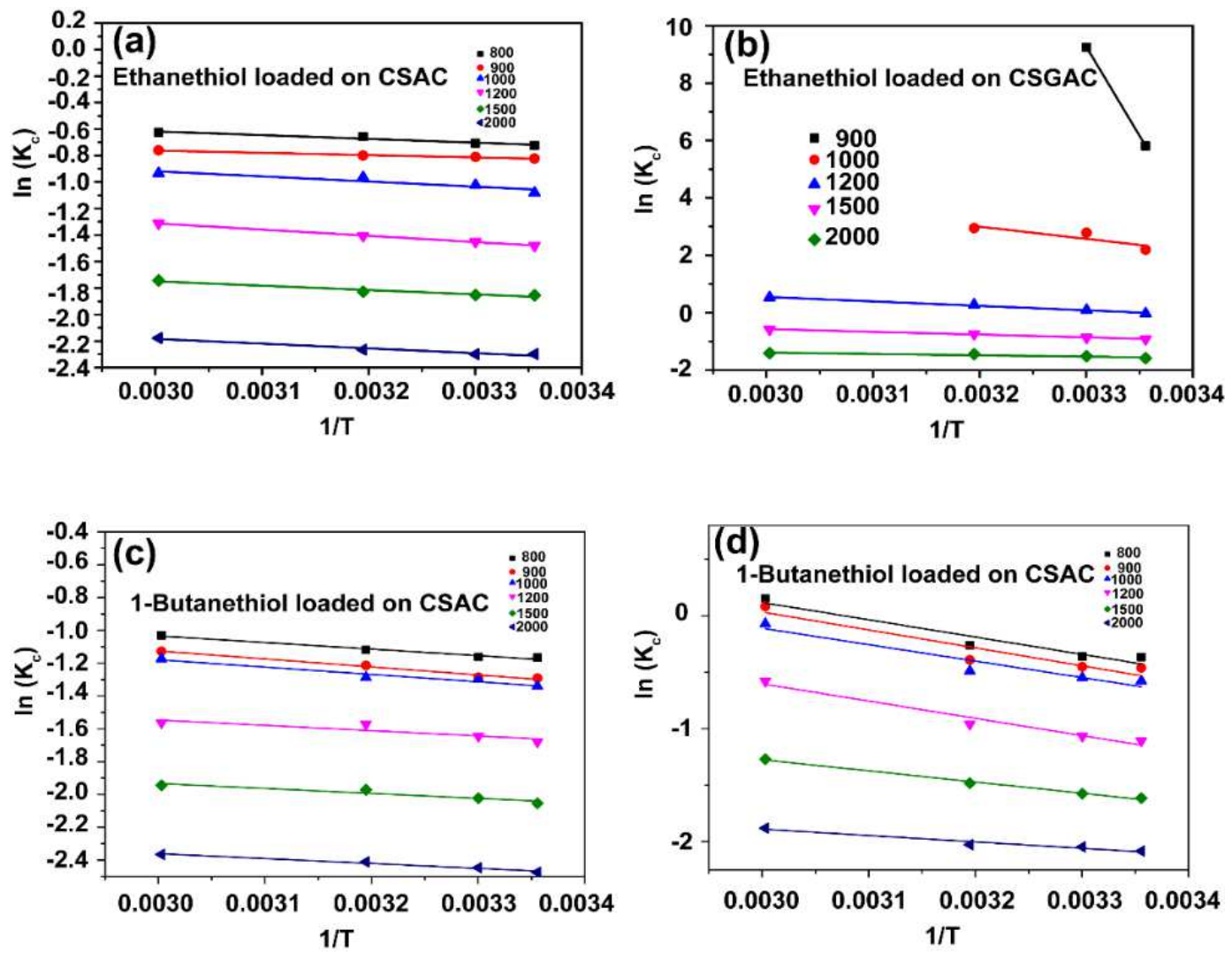

Fig. 7.

674

675

676

677

678

679

680

681

682 


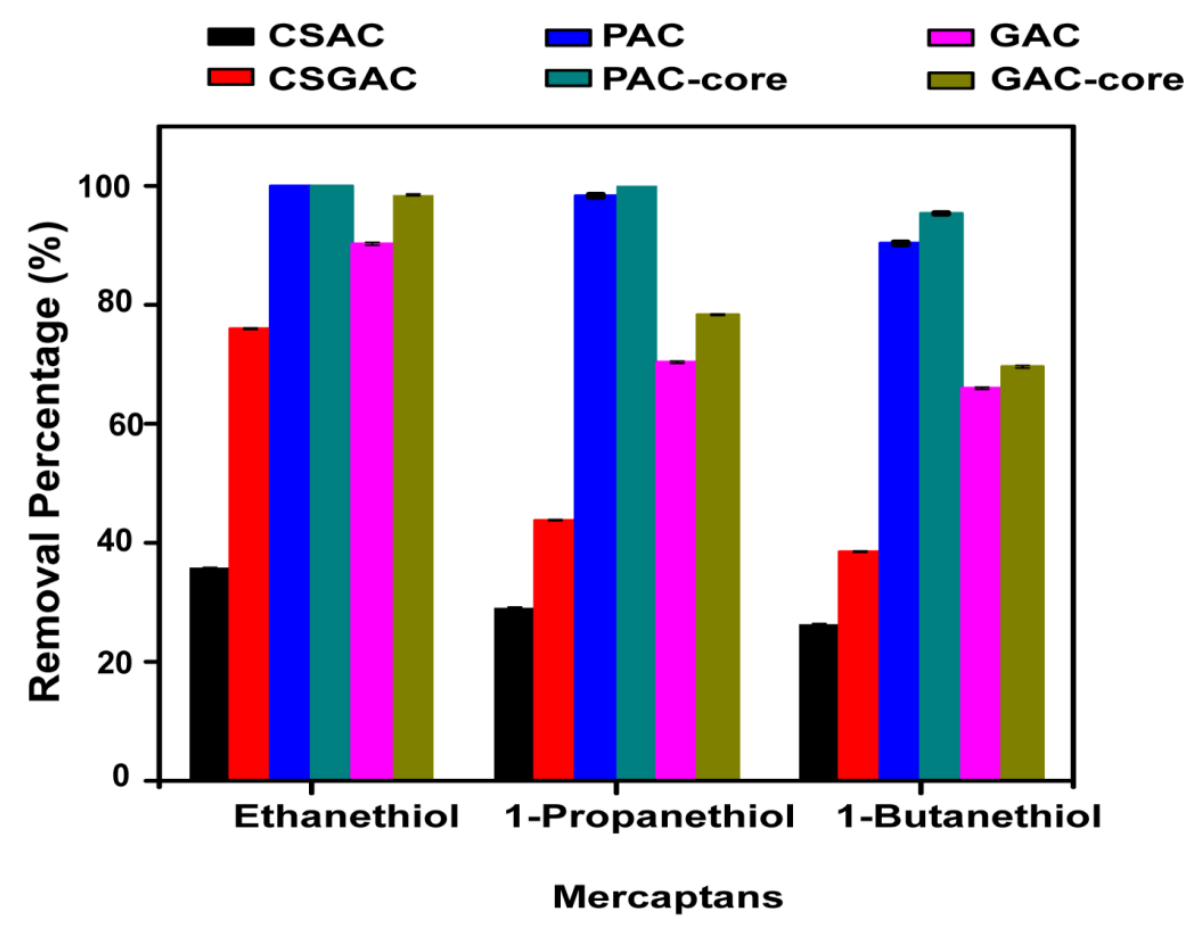

684

Fig. 8.

685

686

687

688

689

690

691 

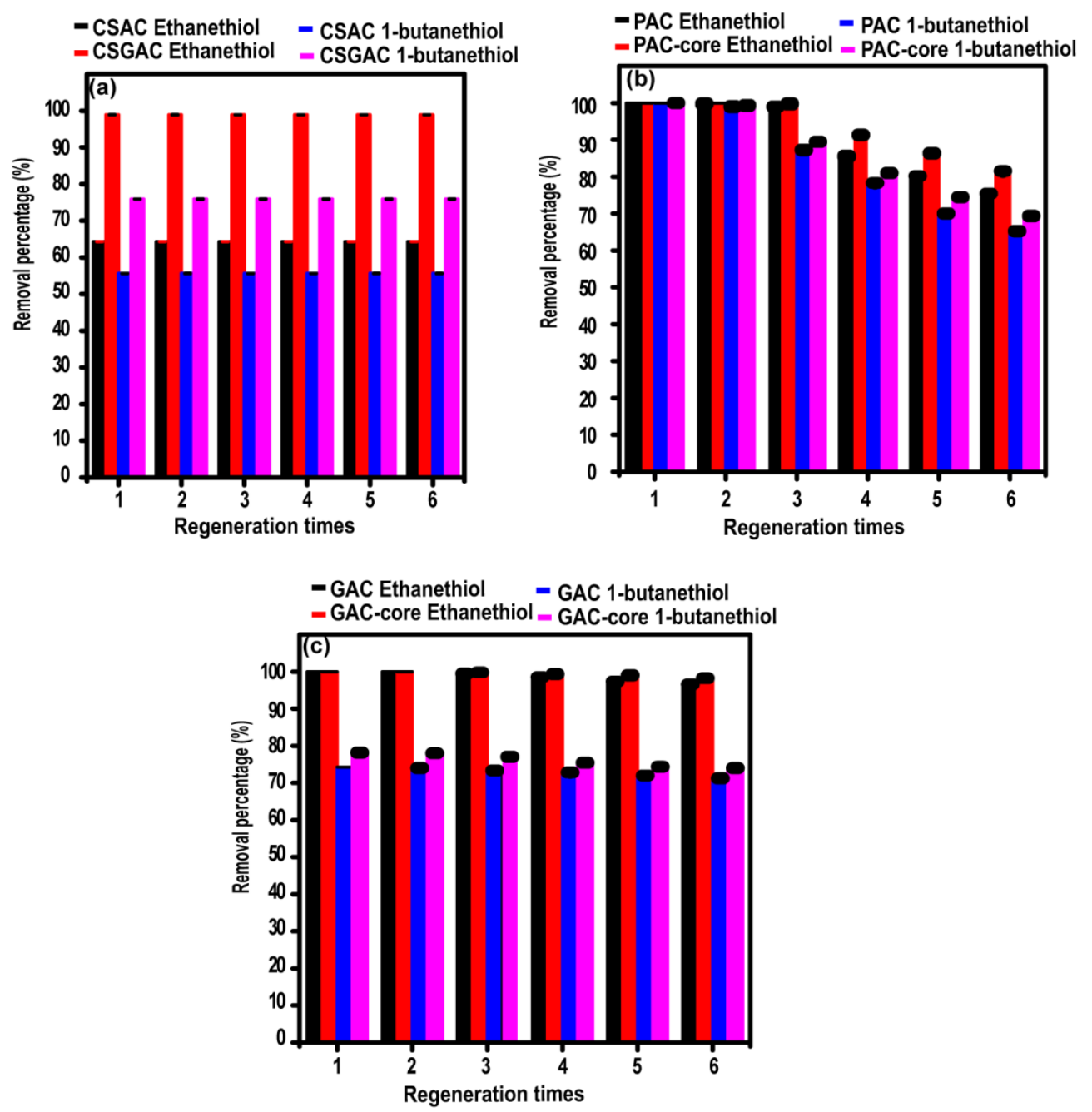

Fig. 9. 

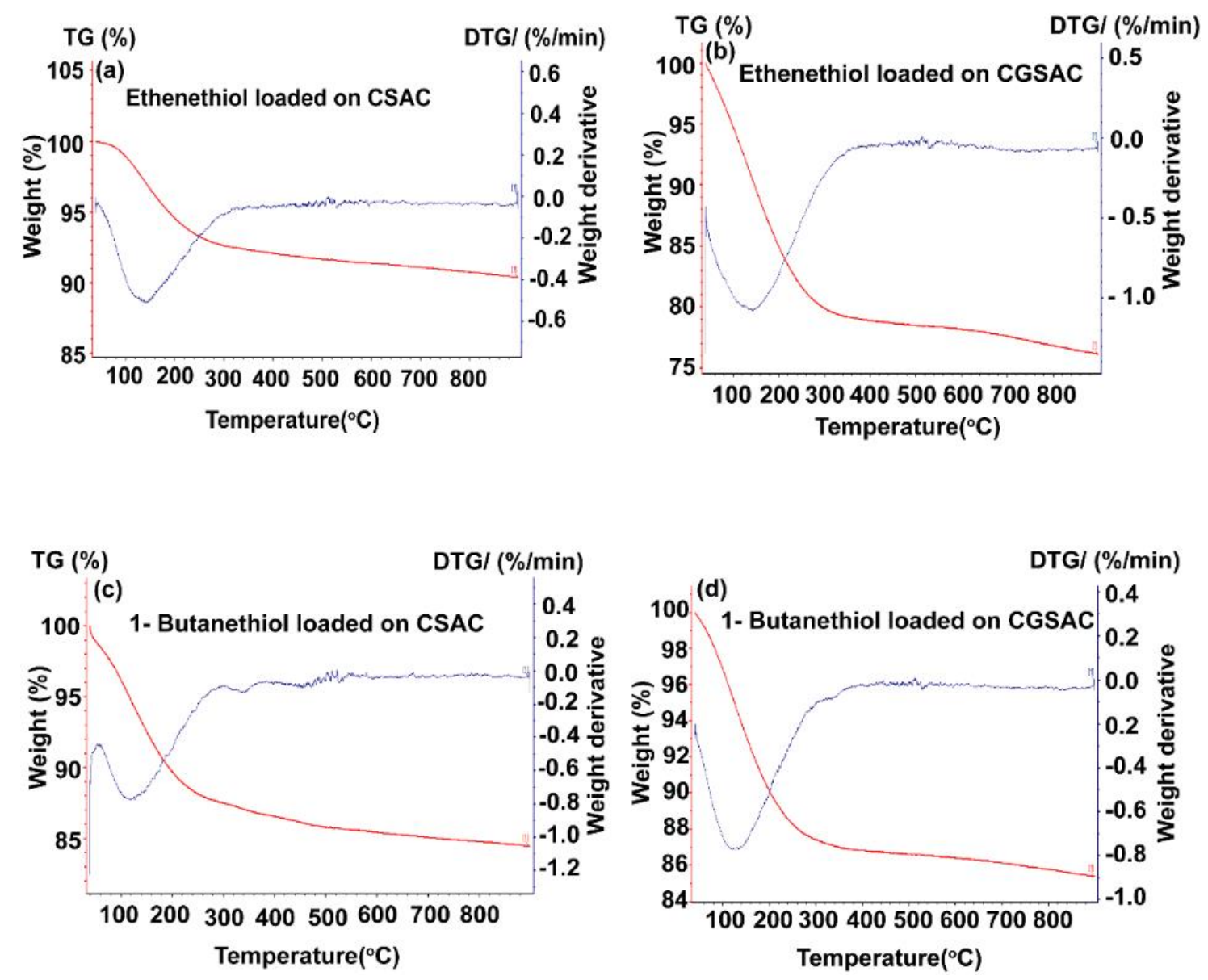

701

Fig. 10.

702

703

704

705

706

707

708

709 


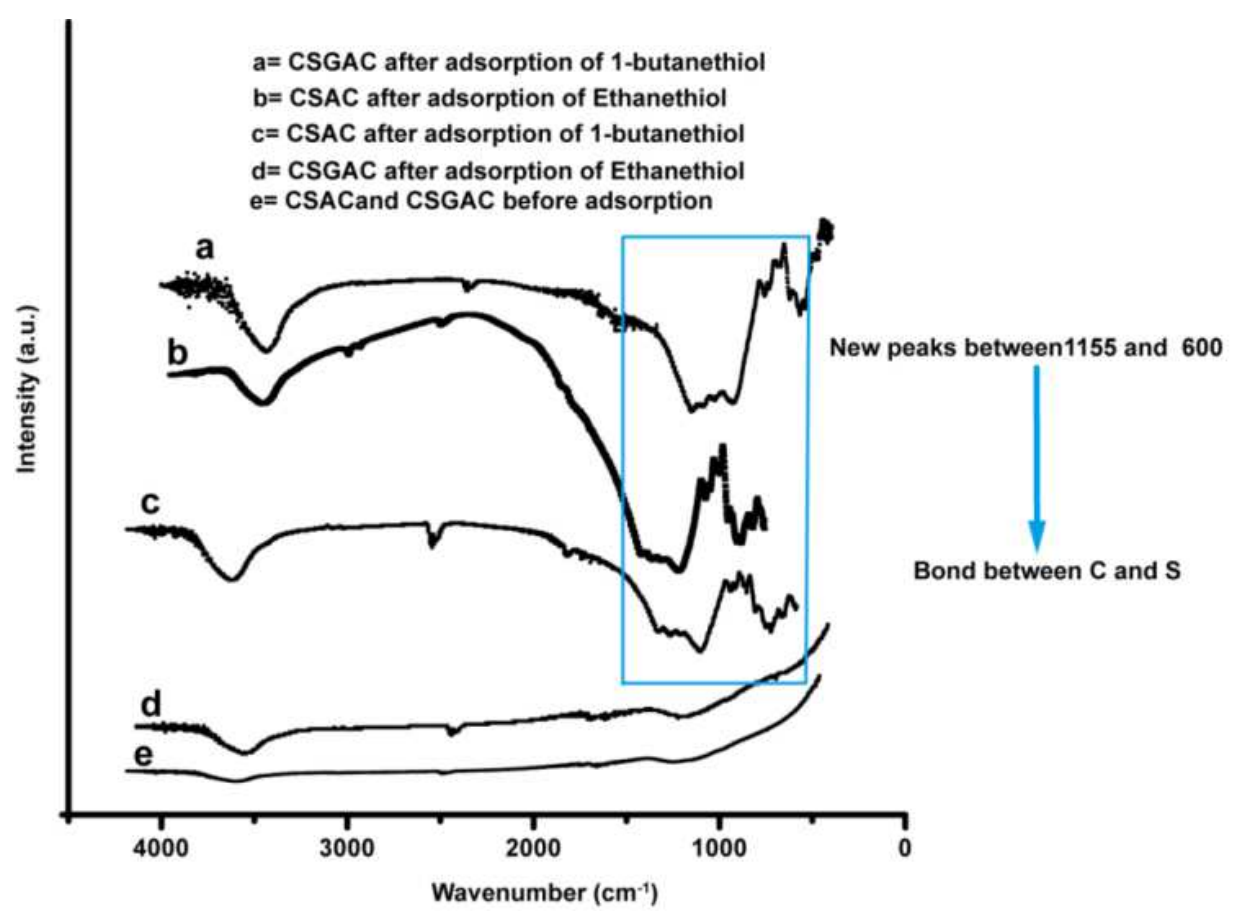

Fig. 11. 


\section{Figures}
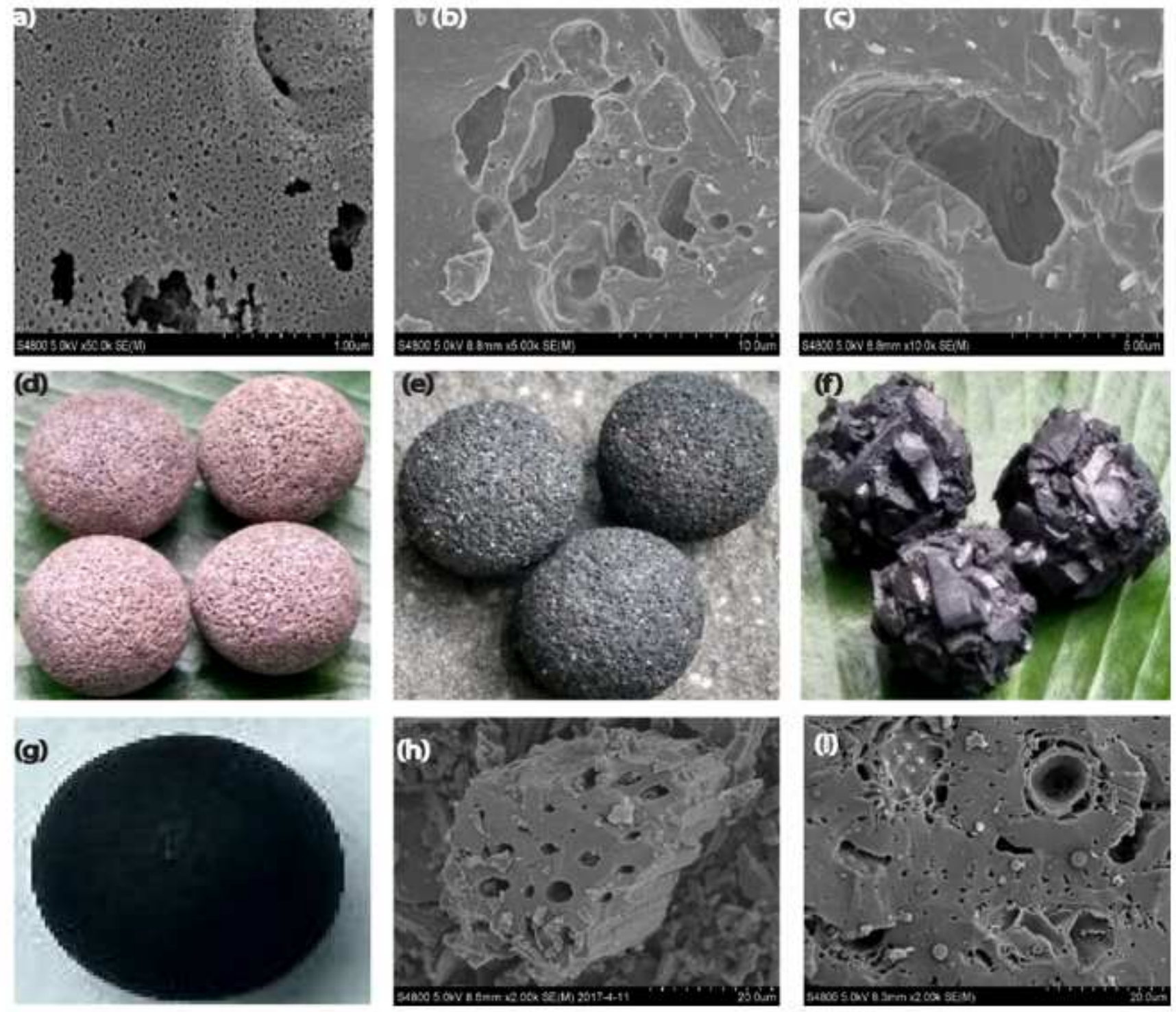

Figure 1

SEM images of shell (a), intra-particle space or void in shell of CSAC (b), CSGAC (c), physical images of CSAC (d), CSGAC (e), GAC-core (f), PAC-core (g), SEM images of PAC-core (h), and GAC-core (i). 

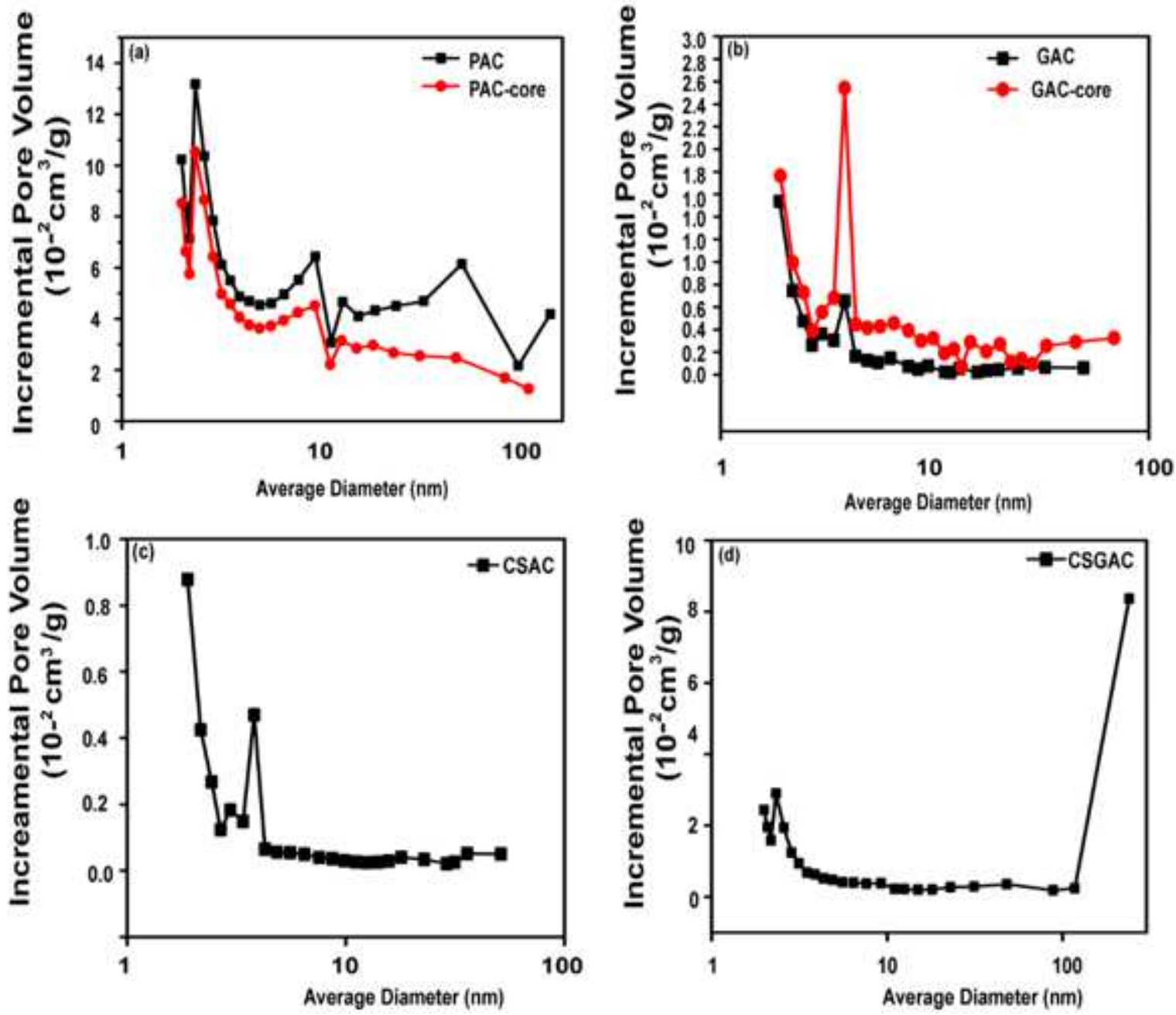

Figure 2

The pore distribution of PAC-based adsorbent (a), GAC-based adsorbent (b), and core-shell ACs (c, d). 


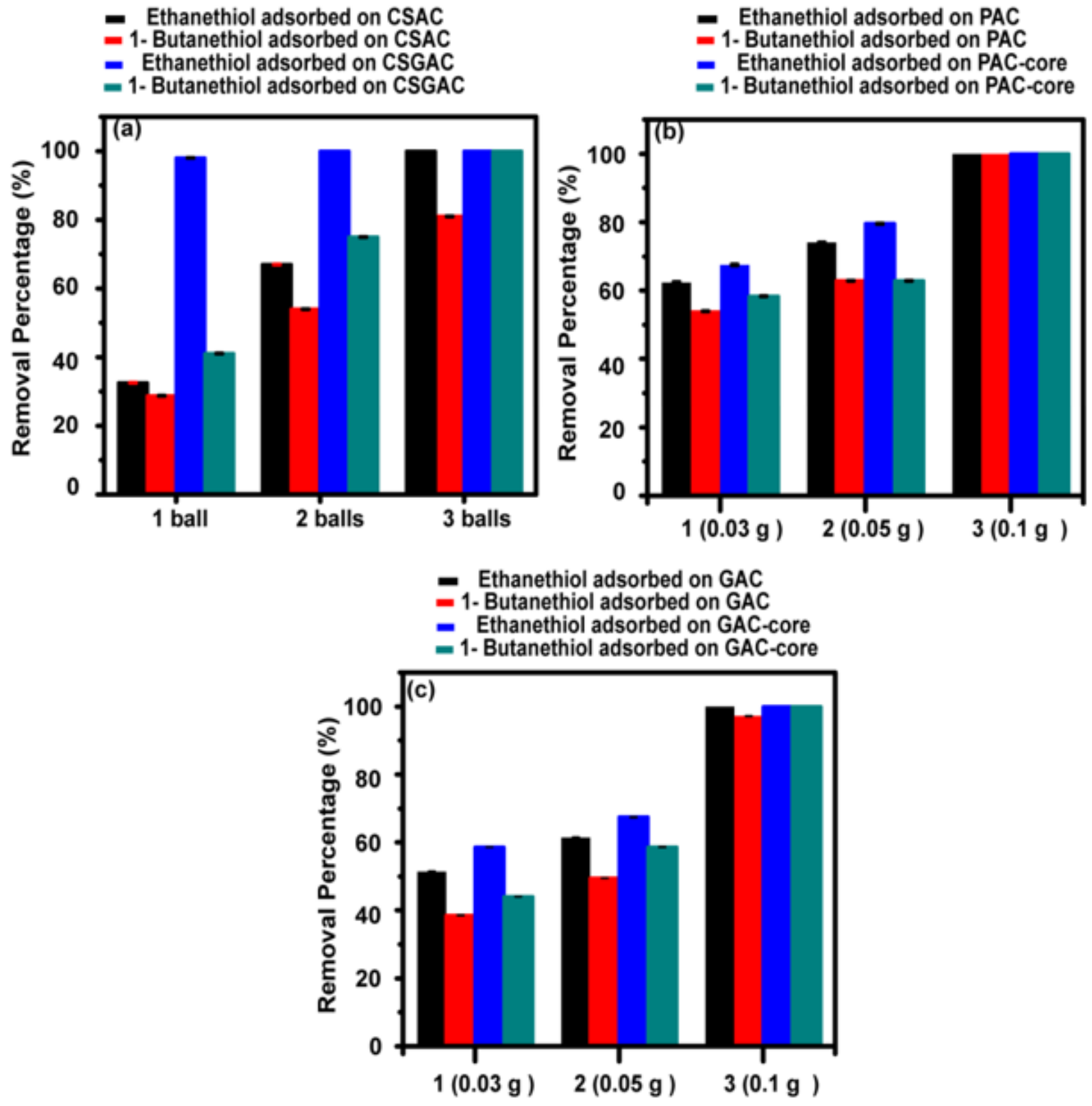

Figure 3

Effect of adsorbent dosage on the mercaptans removal by CSAC and CSGAC (a), PAC-based adsorbents (b), and GAC-based adsorbents(c). (Conditions: $\mathrm{CO}=2000 \mathrm{ppm}, \mathrm{V}=50 \mathrm{~mL}$, mass $=0.24 \mathrm{~g}$ (CSAC), $0.28 \mathrm{~g}$ (CSGAC), $0.05 \mathrm{~g}$ (PAC-core and PAC), and $0.03 \mathrm{~g}$ (GAC-core and GAC)). 

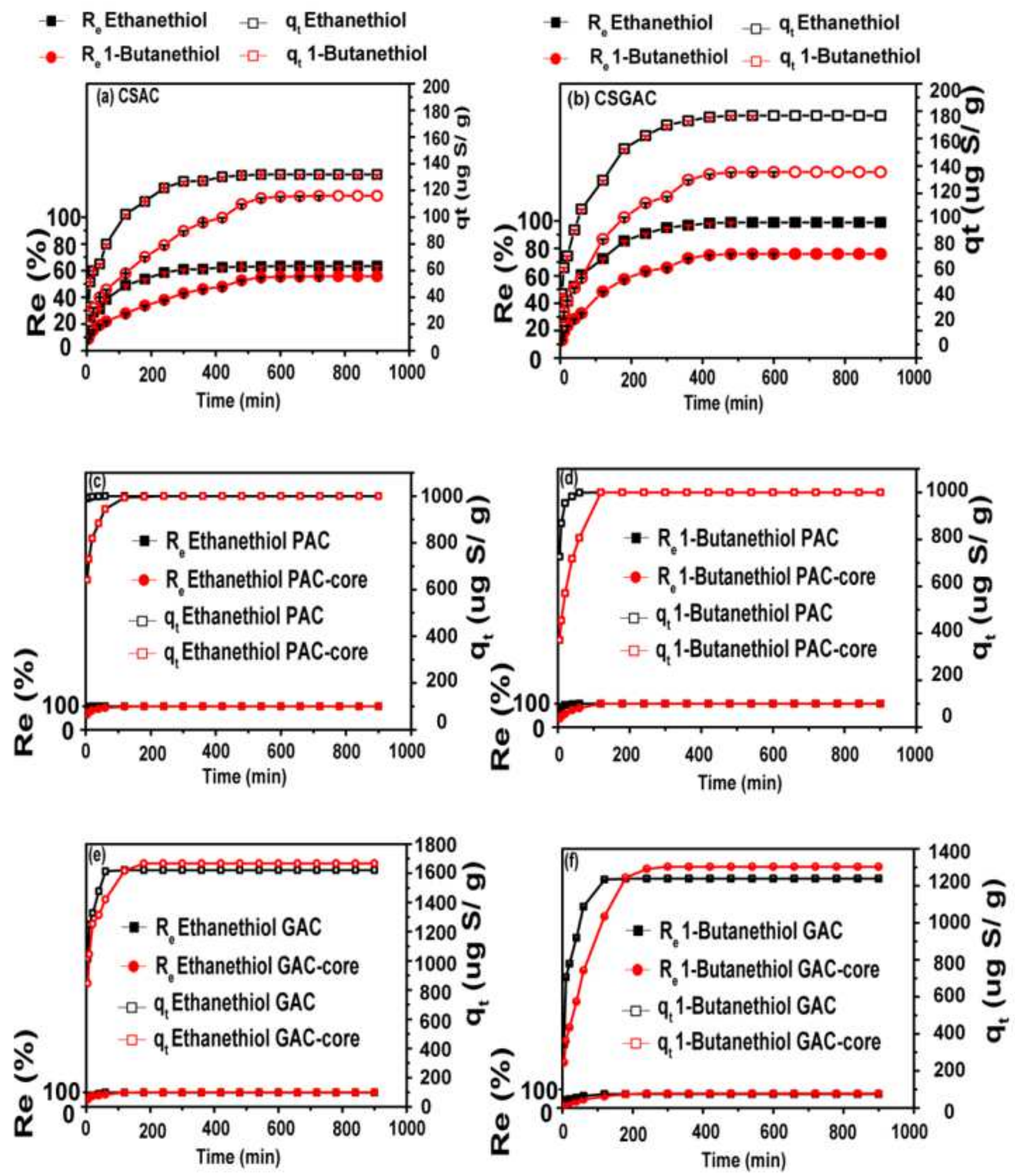

Figure 4

Effect of contact time for CSAC and CSGAC $(a, b)$ and for PAC, PAC-core, GAC, GAC-core (c-f).

(Conditions: $\mathrm{CO}=1000 \mathrm{ppm}, \mathrm{V}=50 \mathrm{~mL}$, mass $=0.24 \mathrm{~g}$ (CSAC), $0.28 \mathrm{~g}$ (CSGAC), $0.05 \mathrm{~g}$ (PAC-core and PAC) and $0.03 \mathrm{~g}$ (GAC-core and GAC). 

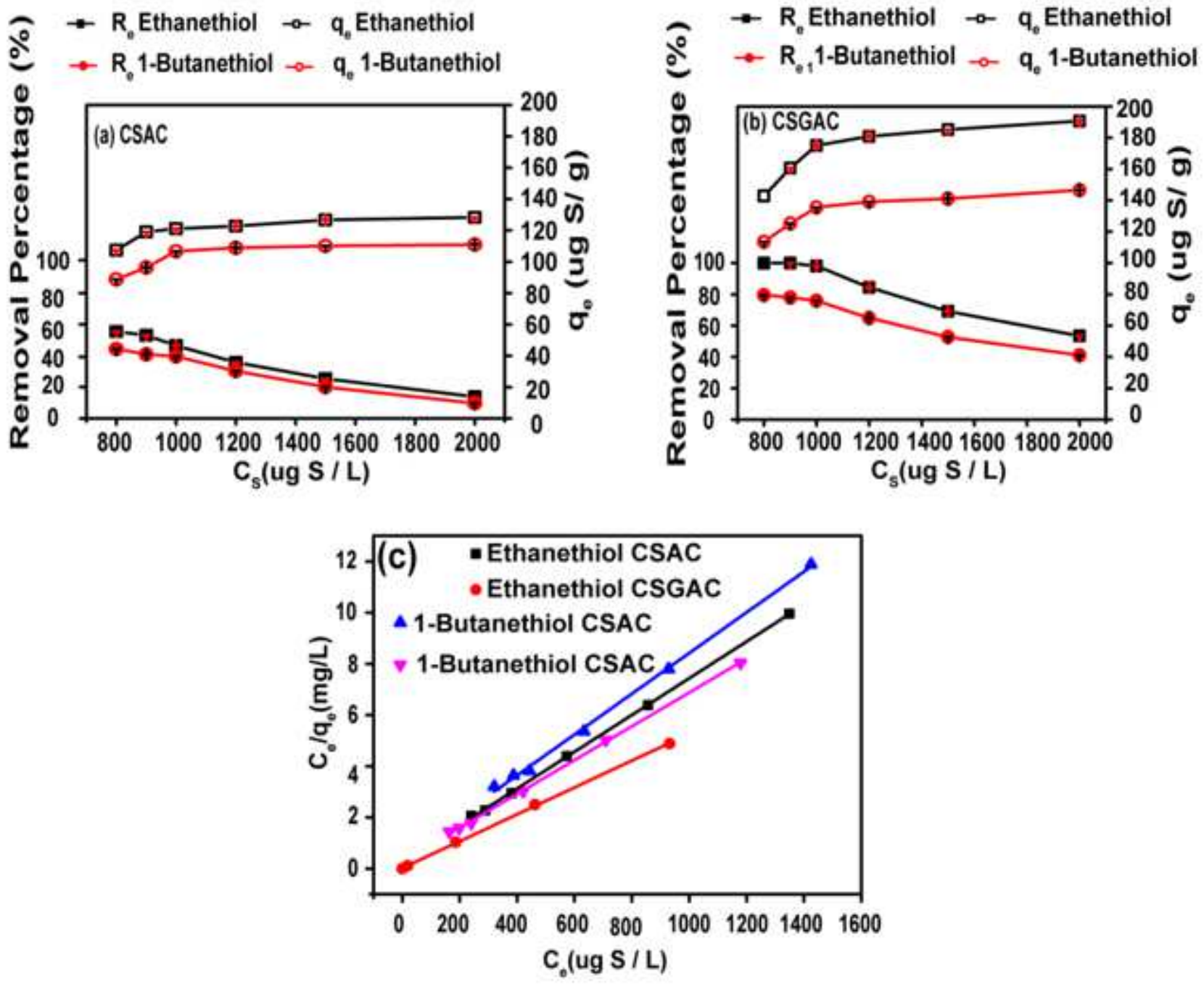

Figure 5

Effect of initial concentration on mercaptans removal (a, b), and Langmuir fitting model (c) 


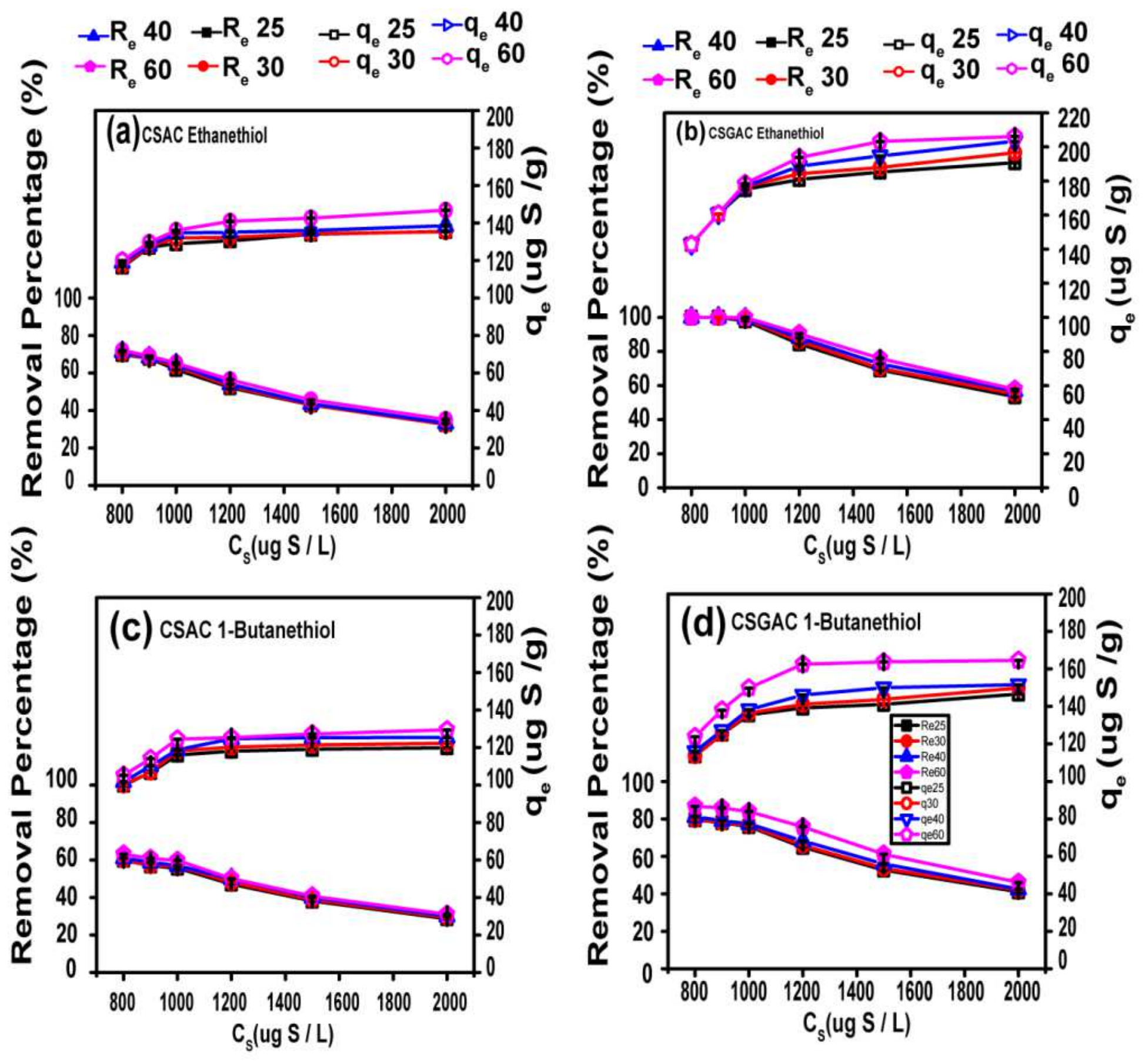

Figure 6

Temperature effect: Ethanethiol adsorbed on CSAC and CSGAC $(a, b)$, 1-Butanethiol adsorbed on CSAC and $\operatorname{CSGAC}(\mathrm{c}, \mathrm{d})$. 

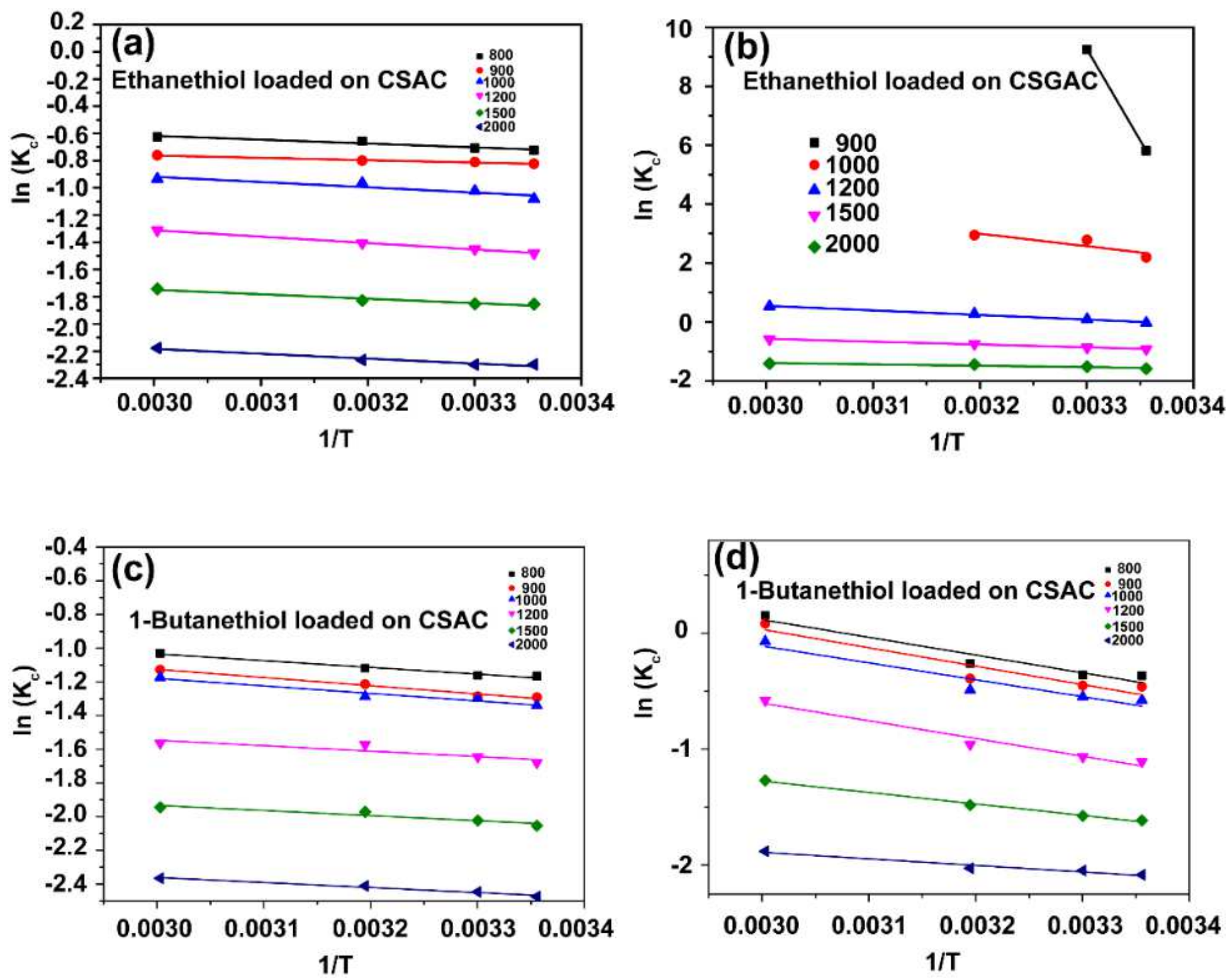

Figure 7

The plot of $K C$ versus $1 / T$ for determination of mercaptans removal reaction enthalpy. 


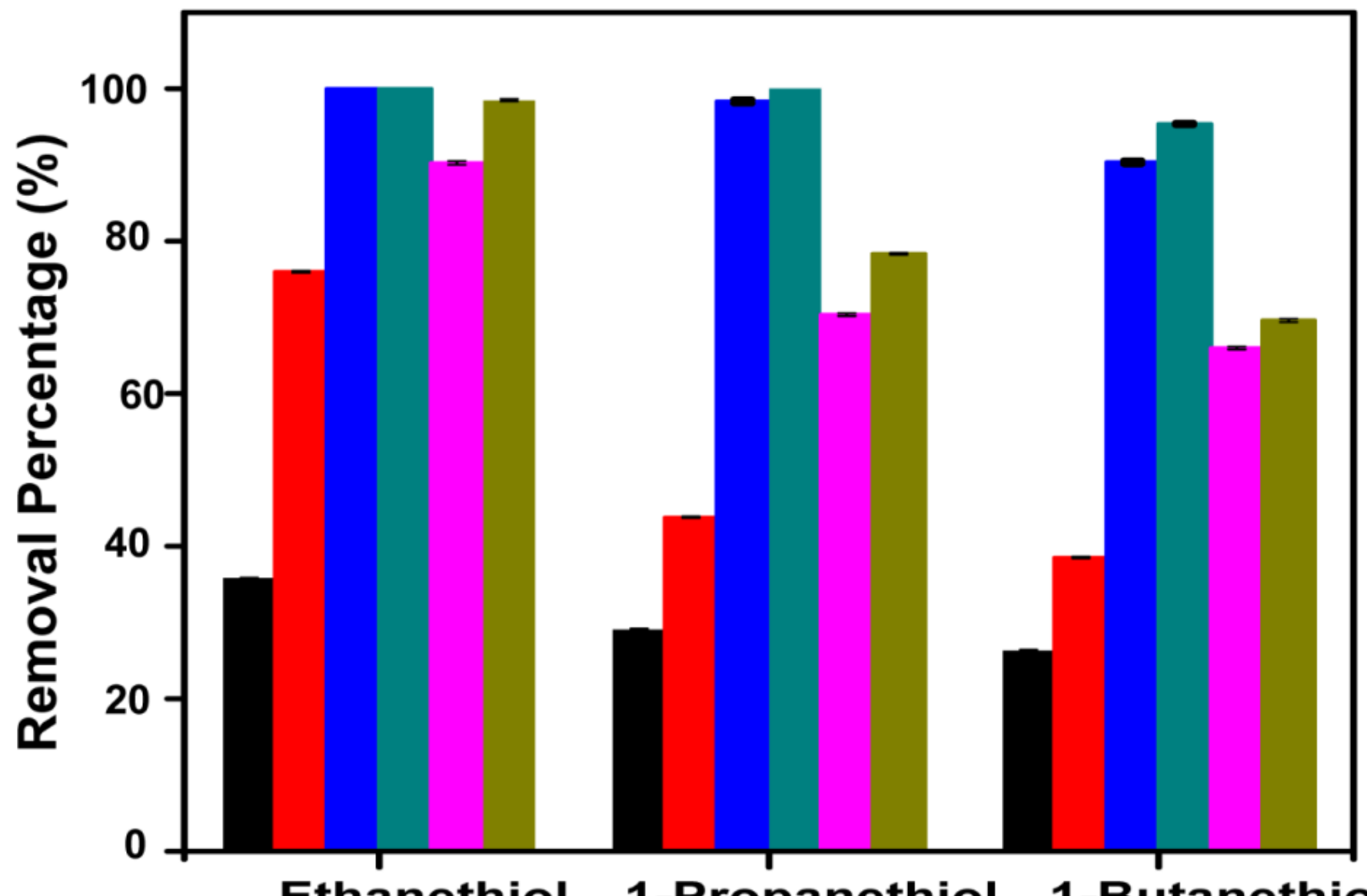

Ethanethiol 1-Propanethiol 1-Butanethiol

\section{Mercaptans}

Figure 8

Adsorption competition of mercaptans by core- shell ACs, PAC-based adsorbents and GAC-based adsorbents. (Conditions: $\mathrm{C} 0=1000 \mathrm{ppm}, \mathrm{V}=50 \mathrm{~mL}$, mass $=0.24 \mathrm{~g}$ (CSAC), $0.28 \mathrm{~g}$ (CSGAC), $0.05 \mathrm{~g}$ (PACcore and PAC) and $0.03 \mathrm{~g}$ (GAC-core and GAC). 

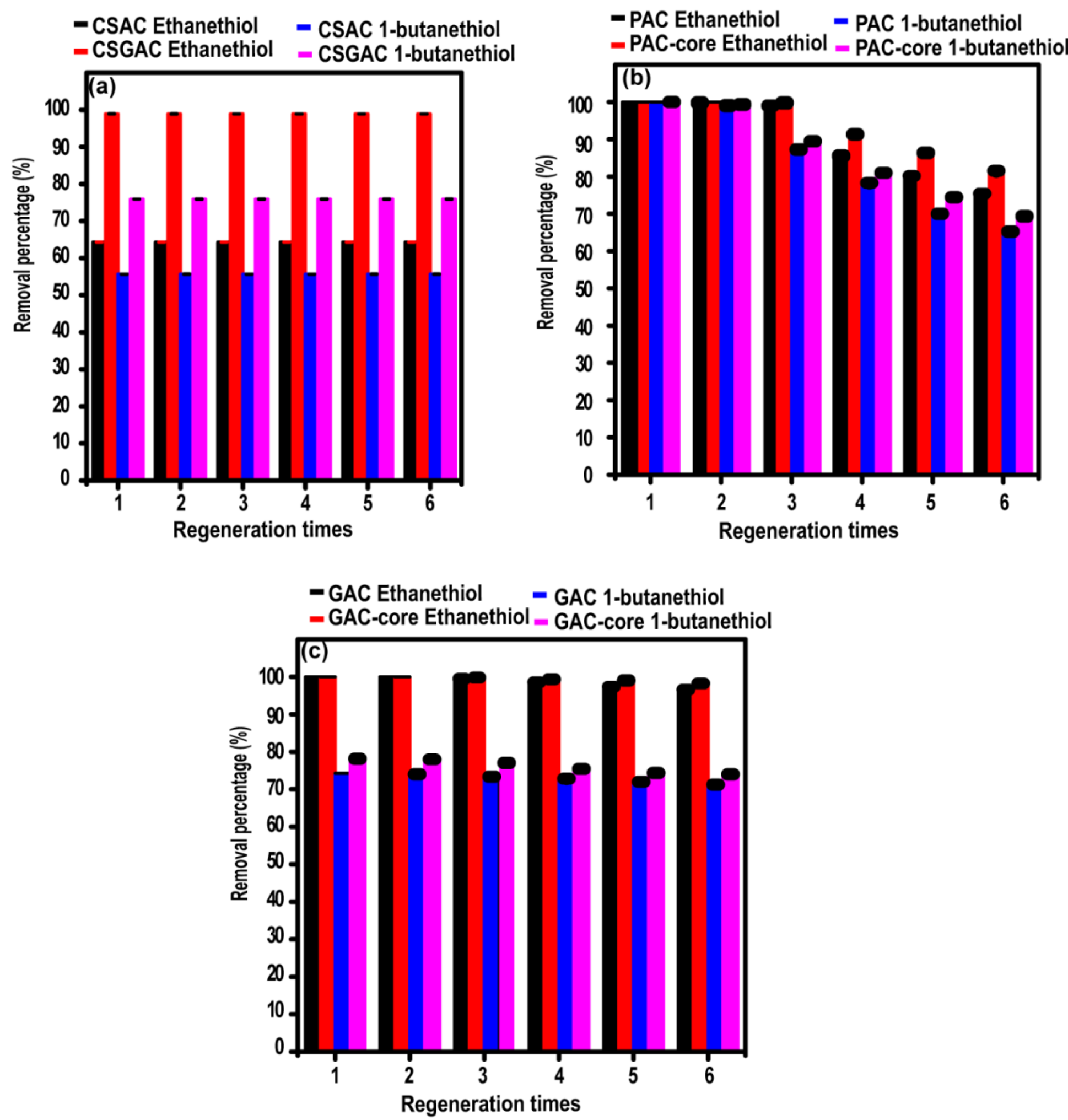

Figure 9

Thermal regeneration of mercaptans by core-shell AC (a) and PAC and GAC based adsorbents $(b, c)$. 

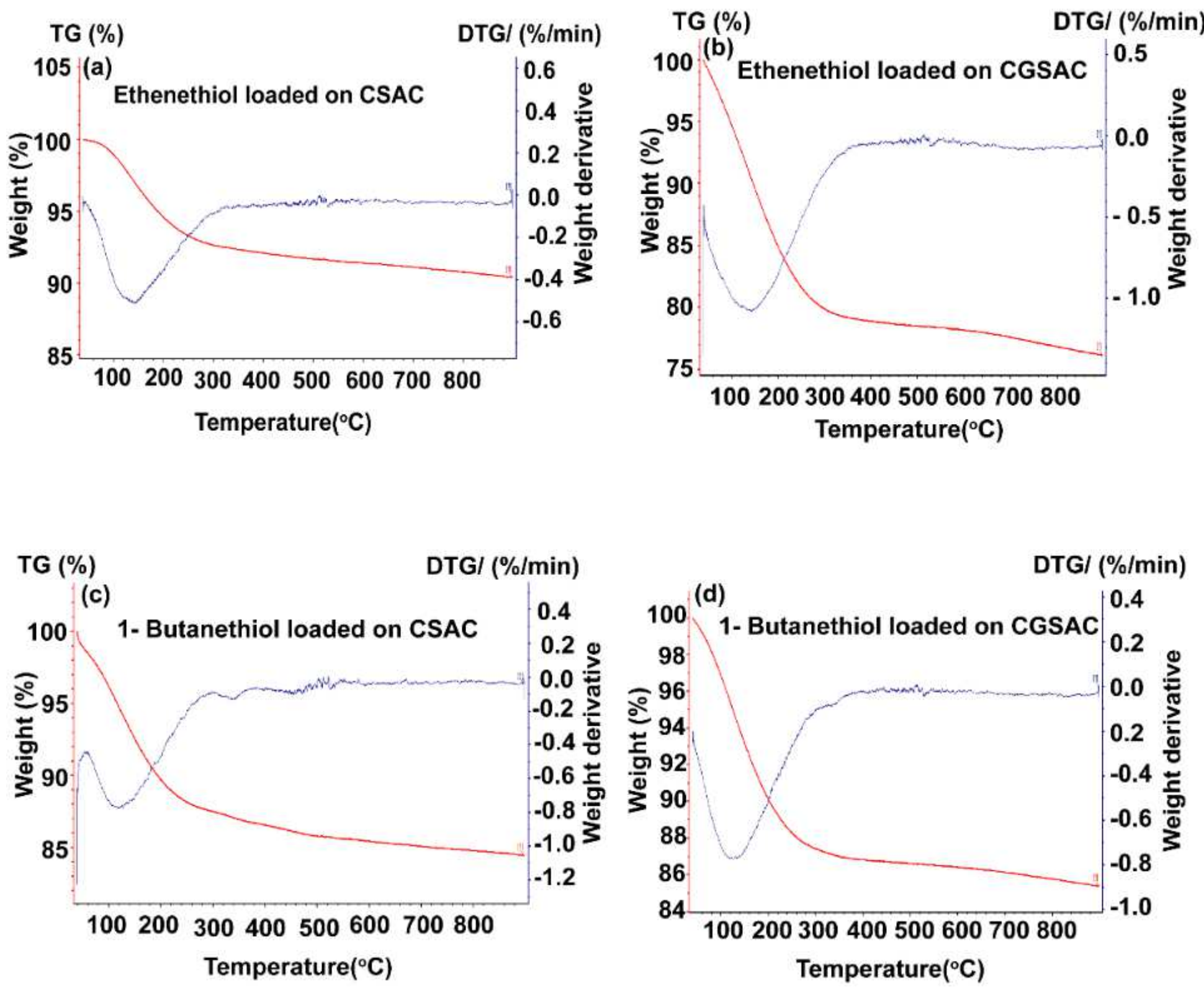

Figure 10

TG and DTG curves of treated CSAC and CSGAC. 


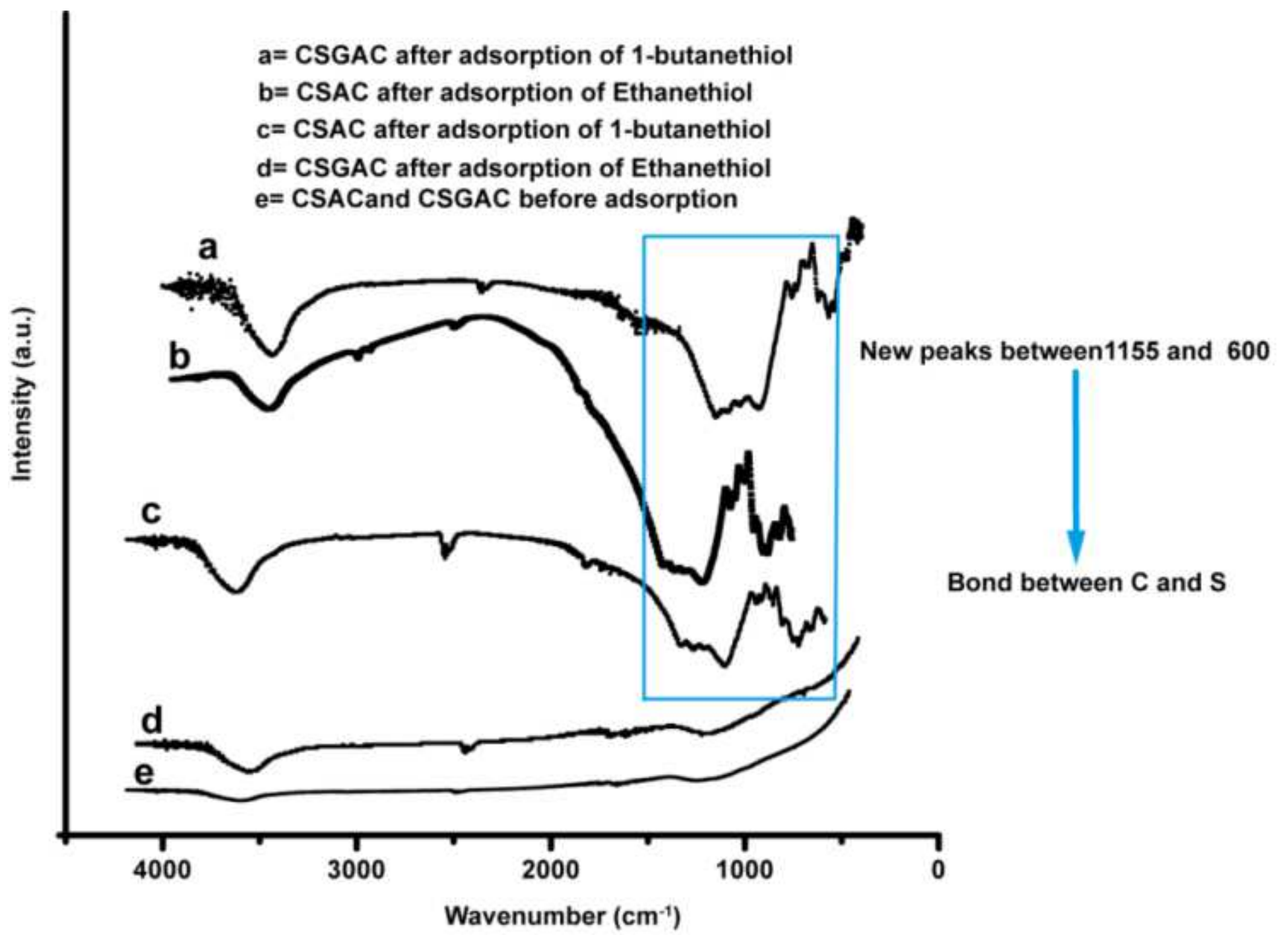

Figure 11

FTIR spectra of pristine and treated CSAC and CSGAC.

\section{Supplementary Files}

This is a list of supplementary files associated with this preprint. Click to download.

- GraphicalAbstract.png

- Supplementarymaterial.docm 